\title{
DOCUMENTATION
}

\section{LES ANTIBIOTIQUES \\ DANS L'ALIMENTATION ANIMALE (suite)}

PAR

\section{J. P. VACHEL ET R. FÉVRIER}

Station de Recherches sur l'Elevage

Centre National de Recherches zootechniques, Jouy-en-Josas

\section{V - ÉtUde PaRticulière DES ANTIBIOTIQUES CHEZ LE PORC}

\section{a) LE PORC EN CROISSANCE}

\section{$\left.I^{0}\right)$ Croissance}

C'est surtout le porcelet qui est sensible aux antibiotiques; il peut en recevoir dès l'âge de 2 jours (BOHSTEDT I950). Comparant l'action de la Streptomycine, de l'Auréomycine et d'un APF brut sur des porcelets âgés de 2 jours à 4 semaines, SHEFNICK et al. (I950) concluent que 1'Auréomycine agit plus favorablement que la Streptomycine. Une combinaison des deux donne le meilleur résultat.

De même, Nfsheim et al. (I950 $b$ ) obtiennent une augmentation de croissance et une diminution de l'indice de consommation significatives pendant 50 jours, chez des porcelets pris à 2 jours et recevant une ration de lait synthétique supplémentée avec $500 \mathrm{mg}$ de Streptomycine par $\mathrm{kg}$ de matière sèche ingérée :

Ration de base : lait synthétique à 30 p. Ioo de protéines.

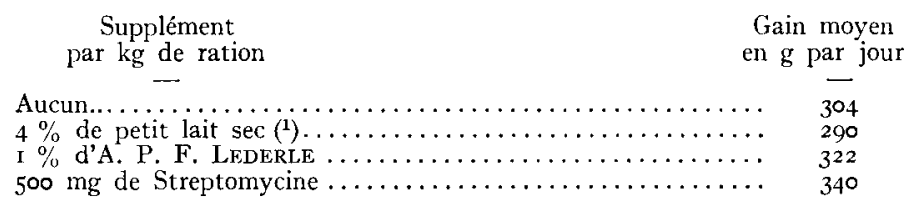

Par contre, une ration semblable supplémentée avec Ioo mg d'Auréomycine, de Streptomycine ou de Pénicilline par $\mathrm{kg}$ de matière sèche n'a donné, au bout de 42 jours, aucun accroissement significatif des gains.

L'étude de l'action des antibiotiques ajoutés à un lait synthétique a

(1) Le petit lait est substitué isocaloriquement à la ration de base. 
été réalisée également par Nesheim et Johnson (I950 a), Wahlstrom et al. (I950), SHEFFy et al. (I95I) et SHEFFy (I952). LUTHER et BRowN (I95 I b), expérimentant sur plus de I000 porcelets, ont étudié l'action des différents antibiotiques et combinaisons d'antibiotiques, des taux de Terramycine, de matières grasses, de matière sèche et de protéines particulières, telles que celles des solubles de poisson.

La technique qu'ils ont adaptée à l'élevage des porcelets (Luther I95I $a$ et $b$ ) est basée sur l'utilisation d'un lait de truie synthétique ('Terralac), composé de :

lait écrémé sec ;

saindoux ;

solubles de poisson ;

vitamines ;

matières minérales.

Ce mélange est additionné de Terramycine, et l'ensemble se présente sous la forme d'une poudre blanche que l'on dilue dans l'eau avant usage. Il remplace totalement le lait de la truie 2 jours après la mise-bas.

Cette méthode est très séduisante par ses avantages techniques, et sa généralisation entraînerait vraisemblablement de sérieux bouleversements dans les techniques actuelles de la production porcine. Mais il convient de noter que certains auteurs ont pu élever des porcelets avec des régimes artificiels dépourvus d'antibiotiques ( $L_{\text {EROY }}$ et $\mathrm{L}_{\mathrm{E}, \mathrm{RY}}$ I946) et que les résultats obtenus sont au moins aussi satisfaisants que ceux de LuTHER. Il n'est donc pas établi que la solution de ce problème implique nécessairement l'usage systématique d'antibiotiques.

Sur les animaux à l'engrais, nous reproduirons tout d'abord les résultats très caractéristiques de quelques expériences rapportées par BEESON(I950) :

I exe expérience, effectuée à l'Université de Floride et aux Laboratoires I,EDERLE :

Ration de base : maïs jaune + Farine d'arachide, supplémentée avec de la vitamine BI2 (dose non précisée).

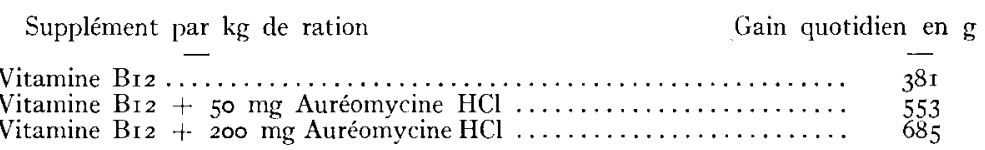

$2^{\mathbf{e}}$ expérience, réalisée au Collège de l'Etat du Michigan:

Ration de base : maïs, tourteau de soja, minéraux divers, vitamines A, D et complexe B.

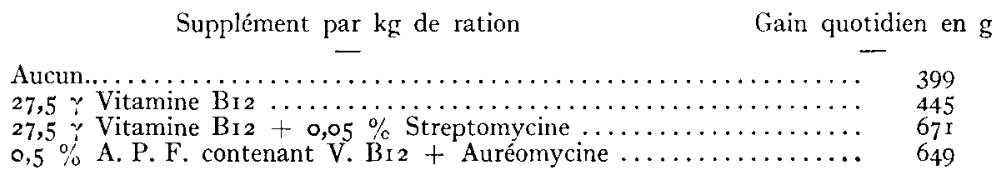


$3^{\mathrm{e}}$ expérience, effectuée à l'Université de Purdue.

Ration de base : mais, tourteau de soja, farine de luzerne, minéraux, vitamines $\mathrm{A}, \mathrm{D}$ et complexe $\mathrm{B}$.

\begin{tabular}{|c|c|c|}
\hline $\begin{array}{l}\text { Supplément par } \mathrm{kg} \\
\text { de ration } \\
\text { - }\end{array}$ & $\begin{array}{l}\text { Gain moyen } \\
\text { quotidien }(\mathrm{g}) \\
-\end{array}$ & $\begin{array}{c}\text { Indice de } \\
\text { consommation } \\
-\end{array}$ \\
\hline & $7^{12}$ & 3,24 \\
\hline $\begin{array}{l}\mathrm{mg} \text { streptomycine. } \\
\mathrm{mg} \text {. Aureomyeine.. }\end{array}$ & $\begin{array}{l}794 \\
826\end{array}$ & $\begin{array}{l}2,75 \\
2,67\end{array}$ \\
\hline
\end{tabular}

Cunha (1950 a) réalise une expérience à la Station agricole expérimentale de Floride, pendant 54 jours, avec des porcs recevant une ration de base composée de maïs, tourteau d'arachide, minéraux ( $\mathrm{Fe}, \mathrm{Cu}, \mathrm{Co}, \mathrm{I}$, $\mathrm{Mn}$ entre autres), les vitamines $\mathrm{A}, \mathrm{D}$ et du complexe $\mathrm{B}, \mathrm{y}$ compris $\mathrm{BI} 2$ et $\mathrm{BI} 2 b$. Les porcelets pèsent $\mathrm{I} 6 \mathrm{~kg}$ au départ :

\begin{tabular}{|c|c|c|c|}
\hline $\begin{array}{c}\text { Supplément par } \mathrm{kg} \\
\text { de ration }\end{array}$ & $\begin{array}{l}\text { Gain moven } \\
\mathrm{g} \text { par jour } \\
\end{array}$ & $\begin{array}{l}\text { Poids final } \\
\text { kg }\end{array}$ & $\begin{array}{l}\text { Indice de } \\
\text { consommation } \\
-\end{array}$ \\
\hline 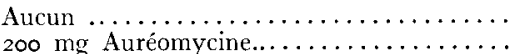 & $\begin{array}{l}340 \\
767\end{array}$ & $\begin{array}{l}36,5 \\
57,5\end{array}$ & $\begin{array}{l}4,68 \\
2,89\end{array}$ \\
\hline
\end{tabular}

Au Collège d'Oklahoma, WhatLEy (I950) réalise une expérience pendant 84 jours, avec des porcs pesant de $I_{3}$ à $I_{7} \mathrm{~kg}$ répartis en 4 lots et recevant tune ration de base ad libitum, constituée de maïs égréné, avec 4 suppléments différents suivant les lots :

Lot I : supplément: farine de poisson, tankage, tourteaux de coton et de soja, farine de luzerne, sels d'oligo-éléments, farine d'os.

Lot 2 : même supplément que $\mathrm{I}$, mais la farine de poisson est remplacée par un APF contenant de l'Auréomycine.

Lot 3 : il ne reçoit ni farine de poisson, ni tankage, mais un APF contenant de 1'Auréomycine.

Lot 4 : il ne reçoit pas de farine de poisson, mais un APF contenant la vitamine $\mathrm{Br} 2$.

$$
\begin{array}{ccccc}
\text { Lot } & \mathrm{I} & 2 & \frac{3}{7} & \frac{4}{708}
\end{array}
$$

Les différences d'indice de consommation ne furent pas significatives.

Citons enfin les travaux de CARPENTER (I949c) sur les propriétés stimulantes de l'Auréomycine et des sous-produits de la fermentation de Streptomyces aureofaciens, ceux de:

MILI.ER et al. (I95I) sur l'action de la Streptomycine alliée à la Vitamine BI2 dans la croissance.

BAKER et al. (I95I) sur 1'action de l'Auréomycine chez des porcs élevés dans des conditions différentes (en dry-lot sur le sol - dans des cages à sol bétonné - dans des enclos avec des bovins).

Beinnison, Catron et al. (I95I) sur l'interaction entre les antibio tiques et l'acide pantothénique dans la croissance. 
TERRILL et KRIDER (I95I) qui avec 1'Auréomycine $(55 \mathrm{mg} / \mathrm{kg}$ ) obtiennent une augmentation de croissance des porcs de $28 \mathrm{p}$. Ioo (régime mais-tourteau de soja).

Terrill et al. (I95I) sur l'emploi, de l'Auréomycine, de la Terramycine et de la Bacitracine.

WALLACE et al. (I95I),sur l'emploi, dans des rations maïs-arachide, de 1'Auréomycine, Bacitracine, Terramycine et Chloromycétine.

BRAUDE et al. (I95 I $a$ et $b$ ), qui n'obtiennent aucune augmentation de croissance avec de l'Auréomycine (Io mg), de la Streptomycine (ro mg), de la Pénicilline $(26,4$ à $137,5 \mathrm{mg} / \mathrm{kg}$ de ration) et des résidus d'antibiotiques, en utilisant des rations contenant de la farine de poisson.

\section{$2^{\circ}$ Durée de l'apport des antibiotiques}

Ils agissent sur la croissance des porcs depuis leur naissance jusqu'à la fin de leur engraissement. Il est donc indispensable, d'après BEESON (I95I b), de continuer la distribution des antibiotiques pendant toute la durée de l'engraissement du porc, c'est-à-dire jusqu'à go kg (dans la mesure où on recherche, jusqu'à l'abattage, une croissance aussi rapide que possible. Cependant, en fin d'engraissement, une croissance rapide risque d'augmenter le pourcentage de tissu adipeux, ce qui diminue la valeur de la carcasse).

I'auteur rapporte les expériences suivantes, qui démontrent cette nécessité :

rere expérience, réalisée à Purdue par Vestal. (1950).

On utilise 3 lots de porcs recevant comme ration de base du maïs entier ad libitum, un concentré protéique constitué de :

80 p. Ioo de tourteau de soja;

Io p. Ioo de farine de luzerne ;

Io p. Ioo de minéraux. ; et un mélange minéral.

Lot I : régime de base.

Lot II : régime de base + I2 $\mathrm{mg}$ d'Auréomycine par $\mathrm{kg}$ de concentré protéique, jusqu'à ce que les animaux pèsent $55 \mathrm{~kg}$ environ. Au delà, régime de base seul.

Lot III : même régime que II, mais l'Auréomycine est distribuée jusqu'au poids de Ioo $\mathrm{kg}$.

On constate que, 7 jours après la suppression de l'Auréomycine, les porcs du lot II diminuent leurs gains de poids et se développent à peu près à la même vitesse que le lot témoin : 
Résultats de croissance en fin d'engraissement

$$
\underset{\text { Gain moyen quotidien }(\mathrm{g})}{\frac{\text { Lots }}{665}} \quad \frac{\text { I }}{695} \quad \frac{\text { II }}{785}
$$

$2^{\mathrm{e}}$ expérience, réalisée à Purdue par Vestal (I950)

Du même type que la précédente. On utilise de la Terramycine à la dose de $\mathrm{I} 32 \mathrm{mg} / \mathrm{kg}$ de concentré protéique, avec du mais ad libitum. Elle conduit à des résultats semblables.

$3^{\mathrm{e}}$ expérience, réalisée par HANSON et al. (I95 I a)

Les essais portent sur 8 lots de 3 porcs chacun. La ration de base comprend du maïs jaune broyé et un supplément constitué de :

46 p. Ioo de tourteau de soja en expellers;

20 p. Ioo de tankage à 60 p. Ioo de protéines;

20 p. roo de farine de luzerne;

Io p. roo de tourteau de lin ;

2 p. Ioo de farine d'os ;

2 p. Ioo de sel iodé.

Le lot 1 reçoit une ration de base à i 8 p. Ioo de protéines, comprenant 66 p. Ioo de maïs et 33 p. roo de supplément, jusqu'à ce que les animaux pèsent $56 \mathrm{~kg}$. Au delà, la ration de base contient $16 \mathrm{p}$. Ioo de protéines, avec $77,8 \mathrm{p}$. Ioo de maïs et $22,2 \mathrm{p}$. Ioo de supplément.

Le lot 2 reçoit la même ration de base que le lot $\mathrm{I}+$ II $\gamma$ de vitamine $\mathrm{BI} 2$ par $\mathrm{kg}$.

Les lots $3-5-7$ reçoivent la même ration que le lot $2+$ II $\mathrm{mg} / \mathrm{kg}$ d'Auréomycine (A), de Terramycine ( $T$ ) ou de Pénicilline (P) respectivement, jusqu'à ce que les animaux pèsent $56 \mathrm{~kg}$. Au delà, on supprime les antibiotiques et les lots ont la ration du lot 2 .

Les lots 4-6-8 ont la même ration que, 3, 5, 7, mais les antibiotiques sont distribués jusqu’à go kg.

I) Résultats de croissance depuis le sevrage $(15 \mathrm{~kg})$ jusqu'à $56 \mathrm{~kg}(55$ à 58,5$)$

\begin{tabular}{|c|c|c|c|c|}
\hline $\begin{array}{c}\text { Lot } \\
n^{0}\end{array}$ & $\begin{array}{c}\text { Supplément à la ration } \\
\text { par kg }\end{array}$ & $\begin{array}{c}\text { Consommation } \\
\text { de nourriture } \\
\mathrm{kg} / \mathrm{j}\end{array}$ & $\begin{array}{c}\text { Gain de poids } \\
\text { moyen } \\
\mathrm{g} / \mathrm{j}\end{array}$ & $\begin{array}{c}\text { Indice } \\
\text { de consommation } \\
\mathrm{kg}\end{array}$ \\
\hline $\begin{array}{l}1 \\
2 \\
3 \\
4 \\
5 \\
6 \\
7 \\
7\end{array}$ & $\left.\begin{array}{l}\text { Aucun } \\
\text { Vitamine } \mathrm{B}_{12} \\
\mathrm{~B}_{12}+\text { Aurémycine } \\
\mathrm{B}_{12}+\text { Auréomycine } \\
\mathrm{B}_{12}+\text { Terramycine } \\
\mathrm{B}_{12}+\text { Terramycine } \\
\mathrm{B}_{12}+\text { Pénicilline } \\
\mathrm{B}_{12}+\text { Pénicilline }\end{array}\right\} \mathrm{T}$ & $\begin{array}{l}1,54 \\
\mathrm{I}, 63 \\
\mathrm{I}, 95 \\
2,00 \\
\mathrm{I}, 8 \mathrm{I} \\
\mathrm{I}, 8 \mathrm{I} \\
\mathrm{I}, 77 \\
\mathrm{I}, 77\end{array}$ & $\begin{array}{l}476 \\
53 \mathrm{I} \\
62 \mathrm{r} \\
658 \\
594 \\
631 \\
599 \\
612\end{array}$ & $\begin{array}{l}3,27 \\
3,10 \\
3,15 \\
3,04 \\
3,02 \\
2,91 \\
2,96 \\
2,85\end{array}$ \\
\hline
\end{tabular}


Les antibiotiques :

- augmentent les gains de poids et la consommation de nourriture,

- diminuent l'indice de consommation.

2) Résultats de croissance et d'engraissement de 56 à $90 \mathrm{~kg}$

\begin{tabular}{|c|c|c|c|c|}
\hline $\begin{array}{l}\text { Lot } \\
n^{0}\end{array}$ & $\begin{array}{c}\text { Supplément à la ration } \\
\text { par kg }\end{array}$ & $\begin{array}{c}\text { Consommation } \\
\text { de nourriture } \\
\mathrm{kg} / \mathrm{j}\end{array}$ & $\begin{array}{c}\text { Gain de poids } \\
\text { moyen } \\
\mathrm{g} / \mathrm{j}\end{array}$ & $\begin{array}{c}\text { Indice } \\
\text { de consommation } \\
\mathrm{kg}\end{array}$ \\
\hline $\begin{array}{l}\text { I } \\
2 \\
3 \\
4 \\
5 \\
6 \\
7 \\
8\end{array}$ & $\begin{array}{l}\text { Aucun } \\
\text { Vitamine } B_{12} \\
\text { Vitamine } B_{12} \\
B_{12}+\text { Auréomycine } \\
\text { Vitamine } B_{12} \\
B_{12}+\text { Terramycine } \\
\text { Vitamine } B_{12} \\
B_{12}+\text { Pénicilline }\end{array}$ & $\begin{array}{l}2,68 \\
3,22 \\
3,04 \\
3,54 \\
3,08 \\
3,40 \\
2,86 \\
3,27\end{array}$ & $\begin{array}{l}689 \\
857 \\
794 \\
871 \\
762 \\
894 \\
748 \\
835\end{array}$ & $\begin{array}{l}3,86 \\
3,79 \\
3,91 \\
4,06 \\
4,07 \\
3,83 \\
3,82 \\
3,88\end{array}$ \\
\hline
\end{tabular}

La suppression des antibiotiques (3-5-7) diminue la consommation quotidienne de nourriture et, semble-t-il, par voie de conséquence, la vitesse de croissance, qui devient même inférieure à celle du lot témoin. L'indice de consommation par contre n'est pas modifié.

\section{3) Résultats de la période complète $(15$ à $90 \mathrm{~kg})$}

L'action des antibiotiques, particulièrement de l'Auréomycine, sur la croissance des porcs est très nette quand on compare ces résultats avec ceux des lots I et 2. En conséquence, les animaux ont atteint le poids de go $\mathrm{kg}$ six semaines avant les animaux témoins. La distribution des antibiotiques jusqu'à $57 \mathrm{~kg}$ seulement n'a provoqué une diminution de la période d'engraissement que de 3 à 4 semaines. Cependant, l'indice de consommation n'a pas été amélioré par les différents suppléments, d'une façon sensible.

\begin{tabular}{|c|c|c|c|c|}
\hline $\begin{array}{l}\text { Lot } \\
n^{0}\end{array}$ & $\begin{array}{c}\text { Supplément à la ration } \\
\text { par kg }\end{array}$ & $\begin{array}{c}\text { Consommation } \\
\text { de nourriture } \\
\mathrm{kg} / \mathrm{j}\end{array}$ & $\begin{array}{c}\text { Gain de poids } \\
\text { moyen } \\
\mathrm{g} / \mathrm{j}\end{array}$ & $\begin{array}{c}\text { Indice } \\
\text { de consommation } \\
\mathrm{kg}\end{array}$ \\
\hline $\begin{array}{l}\text { I } \\
2 \\
3 \\
4 \\
5 \\
6 \\
7 \\
8\end{array}$ & $\begin{array}{l}\text { Aucun } \\
\text { Vitamine } \mathrm{B}_{12} \\
\mathrm{~B}_{12}+\text { Auréomycine. . } 56 \mathrm{~kg} \\
\mathrm{~B}_{12}+\text { Auréomycine } \\
\mathrm{B}_{12}+\text { Terramycine. } 56 \mathrm{~kg} \\
\mathrm{~B}_{12}+\text { Terramycine } \\
\mathrm{B}_{12}+\text { Pénicilline....5 } \\
\mathrm{B}_{12}+\text { Pénicilline }\end{array}$ & $\begin{array}{l}1,95 \\
2,18 \\
2,40 \\
2,59 \\
2,31 \\
2,31 \\
2,22 \\
2,31\end{array}$ & $\begin{array}{l}549 \\
635 \\
694 \\
739 \\
662 \\
712 \\
658 \\
699\end{array}$ & $\begin{array}{l}3,52 \\
3,40 \\
3,50 \\
3,49 \\
3,50 \\
3,26 \\
3,35 \\
3,32\end{array}$ \\
\hline
\end{tabular}

WALLACE et al. (I95I a) constatent également que la suppression de $2,2 \mathrm{mg}$ d'Auréomycine par $\mathrm{kg}$ de ration à des porcs pesant $45 \mathrm{~kg}$, réduit le gain journalier de poids de 680 à $390 \mathrm{~g}$. 


\section{$3^{\circ}$ Les antibiotiques pour les porcs à la pâture}

Hanson et a1. (I95 I $b$ ) réalisent une expérience pour déterminer si les antibiotiques améliorent une bonne ration distribuée à des porcs placés dans un excellent pâturage de luzerne et de brôme. Ils procèdent à deux séries d'observations, depuis le sevrage jusqu'à go $\mathrm{kg}$. Pendant la période d'allaitement, les animaux ont reçu un supplément de vitamine BI2 et d'Auréomycine. Ils sont mis à la pâture le $6^{\mathbf{e}}$ jour d'expérienct.

La ration de base est composée de mais, tourteaux de soja et de lin, farine de viande et suppléments minéraux.

Les lots expérimentaux reçoivent, en outre, II mg d'Auréomycine et II $\gamma$ de vitamine BI2 par $\mathrm{kg}$ de nourriture, du sevrage à $34 \mathrm{~kg}$ (période I), et respectivement $44 \mathrm{mg}$ et 44 y de 34 à $90 \mathrm{~kg}$.

Le poids des porcelets au départ est de I4,3 $\mathrm{kg}$ dans l'essai I et de I4, I kg dans l'essai 2.

\begin{tabular}{|c|c|c|c|c|c|}
\hline & $\begin{array}{l}\text { Lot } \\
n^{\circ}\end{array}$ & $\begin{array}{c}\text { Supplément à la ration } \\
\text { par kg }\end{array}$ & $\begin{array}{c}\text { Consommation } \\
\text { de nourriture } \\
\mathrm{kg} / \mathrm{j}\end{array}$ & $\begin{array}{c}\text { Gain de poids } \\
\text { moyen } \\
\mathbf{g} / \mathbf{j}\end{array}$ & $\begin{array}{c}\text { Indice de } \\
\text { consommation } \\
\mathrm{kg}\end{array}$ \\
\hline $\begin{array}{l}\text { Essai } 1 \\
\text { Essai } 2\end{array}$ & $\begin{array}{l}I \\
2 \\
3 \\
4\end{array}$ & $\begin{array}{l}\text { I }^{\circ} \text { Résultats de croissance } \\
\text { Aucun } \\
\text { Auréomycine }-\mathrm{B}_{12} \\
\text { Aucun } \\
\text { Auréomycine }-\mathrm{B}_{1 \mathrm{i}}\end{array}$ & \begin{tabular}{|c|} 
uis le seurage \\
$\mathrm{I}, 22$ \\
$\mathrm{I}, 45$ \\
$\mathrm{I}, 63$ \\
$\mathrm{I}, 63$
\end{tabular} & \begin{tabular}{|c|}
$14 \mathrm{~kg}$ ) jusqu'au \\
503 \\
567 \\
540 \\
640
\end{tabular} & $\begin{array}{l}\text { poids de } 34 \mathrm{~kg} \text {. } \\
2,46 \\
2,53 \\
3,03 \\
\mathbf{2 , 5 6}\end{array}$ \\
\hline $\begin{array}{l}\text { Essai } ~ \\
\text { Essai } 2\end{array}$ & $\begin{array}{l}\text { I } \\
2 \\
3 \\
4\end{array}$ & $\begin{array}{l}2^{\circ} \text { Résultats de croissance } \\
\text { Aucun } \\
\text { Auréomycine }-\mathrm{B}_{12} \\
\text { Aucun } \\
\text { Auréomycine }-\mathrm{B}_{12}\end{array}$ & \begin{tabular}{|} 
d'engraissement \\
2,68 \\
$2,8 \mathrm{I}$ \\
2,72 \\
$2,8 \mathrm{I}$
\end{tabular} & 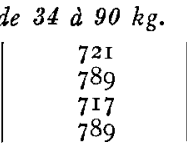 & $\begin{array}{l}3,69 \\
3,50 \\
3,81 \\
3,56\end{array}$ \\
\hline $\begin{array}{l}\text { Essai I } \\
\text { Essai } 2\end{array}$ & $\begin{array}{l}\text { I } \\
2 \\
3 \\
4\end{array}$ & $\begin{array}{l}3^{\circ} \text { Résultats de la période } \\
\text { Aucun } \\
\text { Auréomycine }-\mathrm{B}_{12} \\
\text { Aucun } \\
\text { Auréomycine }-\mathrm{B}_{12}\end{array}$ & $\begin{array}{l}\text { aplète (de } 14 d \\
\quad 2,18 \\
2,31 \\
2,36 \\
2,45\end{array}$ & \begin{tabular}{|r|}
$90 \mathrm{~kg})$. \\
644 \\
712 \\
653 \\
744
\end{tabular} & $\begin{array}{l}3,35 \\
3,24 \\
3,60 \\
3,30\end{array}$ \\
\hline
\end{tabular}

Les conclusions des auteurs sont les suivantes:

I $^{\circ}$ La supplémentation d'une bonne ration avec l'Auréomycine et la Vitamine $\mathrm{Br} 2$ distribuée à des porcs pâturant un excellent fourrage de luzerne et de brôme, a augmenté la consommation journalière de nourriture et la vitesse de croissance, mais n'a pas réduit de façon considérable l'indice de consommation.

$2^{\circ}$ Les porcs du lot expérimental ont atteint $90 \mathrm{~kg}$ environ deux semaines avant les lots témoins.

VESTAL (I950), durant l'été de I950, distribue à de jeunes porcelets placés dans un pâturage de luzerne, un APF à la dose de 0,4 p. Ioo (con- 
tenant 4,4 mg de vitamine BI2 et 3,75\% d'Auréomycine par $\mathrm{kg}$ ). Il obtient : une croissance de $907 \mathrm{~g}$ par jour au lieu de $8 \mathrm{I} 2 \mathrm{~g}$ pour le lot témoin.

Citons enfin PrineGar et al. (I95I) qui ont étudié l'action comparée des antibiotiques chez les porcs en dry-lot et à la pâture, et concluent à leur action bienfaisante.

Sur ce point, l'accord semble complet entre les différents auteurs : l'action bénéfique des antibiotiques sur la croissance n'est pas amoindrie par le pâturage.

\section{$4^{\circ}$ Croissance, consommation et indice de consommation. Leurs variations}

Comme nous avons déjà eu l'occasion de le montrer (FÉVRIER I952), consommation de nourriture, vitesse de croissance, indice de consommation ne sont pas des variables indépendantes, mais au contraire sont liées les unes aux autres dans une certaine mesure. I, 'augmentation de croissance que l'on observe généralement à la suite d'ingestion des antibiotiques pourrait très hien, par exemple, être la conséquence directe d'une augmentation de la consommation de nourriture ; l'abaissement de l'indice de consommation serait à son tour la conséquence de cette augmentation de croissance.

Mais cette amélioration de la croissance peut aussi être due à une augmentation de ce que nous avons appelé l'Efficacité de la ration.

Enfin, il n'est pas exclu que ces deux processus d'intervention se soient simultanément exercés.

Dans l'expérience précitée de HANson et al. (I95 I a) (cf. titre V. $a, 2^{\circ}$ ), dans celles de Briggs et al. (I95I) et de Brown et al. (I95I), les antibiotiques ont nettement augmenté les consommations journalières des animaux.

Reprenant les résultats de HaNson, en utilisant la méthode que nous avons indiquée (FÉVRIER I952) et en prenant le lot 4 comme lot de référence, nous avons calculé les indices de consommation corrigés, ainsi que l'efficacité relative des rations :

\begin{tabular}{|c|c|c|c|c|}
\hline Lot & I & 4 & 6 & 8 \\
\hline $\begin{array}{l}\text { Supplément à la ration.......... } \\
\text { Gain de poids moyen }(\mathrm{g}) \ldots \ldots \ldots \\
\text { Consommation journalière (kg)... } \\
\text { Indices de consommation bruts... } \\
\text { Indices de consommation corrigés. } \\
\text { Efficacité relative des rations. ... }\end{array}$ & $\begin{array}{l}\text { Aucun } \\
549 \\
1,95 \\
3,52 \\
3,17 \\
1,10\end{array}$ & $\begin{array}{c}\text { Auréomycine } \\
739 \\
2,59 \\
3,50 \\
3,50 \\
1,00\end{array}$ & $\begin{array}{c}\text { Terramycine } \\
7 \text { I } 2 \\
2,3 \mathrm{I} \\
3,26 \\
3,24 \\
\mathrm{I}, 08\end{array}$ & $\begin{array}{c}\text { Pénicilline } \\
699 \\
2,31 \\
3,32 \\
3,26 \\
1,07\end{array}$ \\
\hline
\end{tabular}

Malgré son imprécision, cette méthode de calcul nous permet une constatation extrêmement intéressante : il ne semble pas y avoir d'amélioration de l'efficacité de la ration par l'adjonction d'antibiotiques, 
l'augmentation de la consommation quotidienne pouvant à elle seule rendre compte de la diminution très faible de l'indice observé et de l'amélioration de la croissance. Ainsi, dans ce cas, l'effet de l'antibiotique pourrait être réduit à une simple action sur l'appétit de l'animal, par un mécanisme inconnu.

De la même façon, nous avons pris au hasard un certain nombre d'expériences groupant plus de 700 porcs, pour étudier systématiquement les variations des consommations journalières moyennes. Puis, en groupant les lots 2 à 2 , nous avons obtenu des couples constitués de :

- un lot témoin ou lot de contrôle, recevant les rations de base,

- un ou plusieurs lots expérimentaux recevant de l'APF ou un antibiotique, en plus de la ration de base.

Les résultats de ce dépouillement peuvent se présenter sous la forme du tableau ci-dessous :

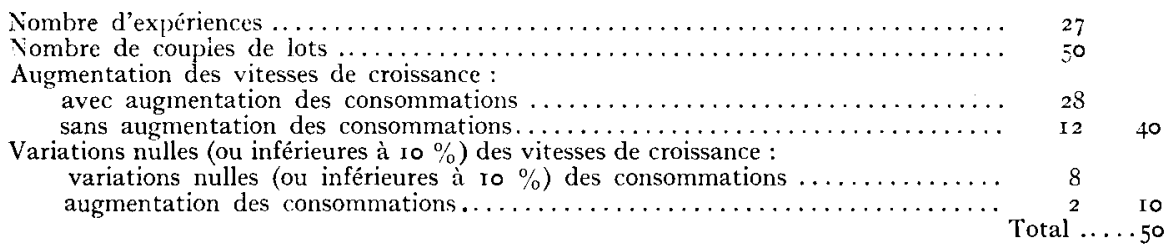

Ainsi, dans 80 p. roo des cas, les antibiotiques ont augmenté la vitesse de croissance de plus de io p. Ioo.

Dans $70 \mathrm{p}$. Ioo de ces cas, cette augmentation des gains journaliers s'est accompagnée d'une augmentation de la consommation de nourriture, qui, en partie ou en totalité, peut en rendre compte.

Ennfin, dans une série de 2 I expériences réalisées à 1'Iowa Agricultural Experiment Station et comprenant 1048 porcs, Catron (I952) aboutit aux conclusions suivantes :

Pour les porcs chétifs, on note avec les antibiotiques une augmentation moyenne de la croissance de $45 \mathrm{p}$. Ioo, et une diminution moyenne de l'indice de consommation de 8 p. Ioo.

Pour les porcs pris du sevrage jusqu'à 34 ou $45 \mathrm{~kg}$, les variations respectives de ces deux grandeurs sont 20 et 9 p. Ioo.

Pour les porcs pris du sevrage jusqu'à $90 \mathrm{~kg}$, les variations sont I6 et $6 \mathrm{p}$. Ioo.

A partir de ces renseignements, on peut calculer que les augmentations de consommation de nourriture sont respectivement, pour ces trois catégories : 33 p. I00- 9 p. I00- 9 p. Ioo.

Or, il est relativement aisé de se rendre compte, par un calcul dans le détail duquel nous n'entrerons pas ici, que cette augmentation de la consommation peut expliquer, pour une très large part, l'augmentation de croissance constatée expérimentalement.

Il nous paraît intéressant de vérifier expérimentalement cette hypo- 
thèse et d'observer, sur des animaux rationnés de la même façon (paired feeding method), l'effet d'une adjonction d'antibiotiques à leur régime. Ainsi, les améliorations de la croissance éventuellement observées ne pourraient pas être rapportées à une augmentation de l'ingestion de nourriture, mais bien à une amélioration réelle de l'efficacité de la ration.

\section{$5^{\circ}$ Entérite infectieuse}

Les antibiotiques détruisent certains germes microbiens et, de cette façon, contrôlent quelques maladies infectieuses du porc, en particulier celles qui se situent au niveau du tractus intestinal. Ainsi protègent-ils considérablement les porcs exposés à une entérite du type infectieux. Cette diminution ou cette suppression des diarrhées est notée par de très nombreux auteurs, notamment :

StOKSTAD (I950); LEPLEY et al. (I950); HANson et al. (I950 a) Catron et al. (I950 $a$, $b$ et $c$ ) ; Burnside, Cunha et al. (I950) ; HeideBRECHT (I950) ; HEIDEBRECHT et al. (I950 a) ; JUKEs et al. (I950 a) ; Bohstedt (I950) ; Briggs et Befison (I950) ; Cuff et al. (I950) ; Cunha et al. (I949 $c$, I950 $a, b$ ),

Nous avons vu par exemple que CATron (r950 a), utilisant de 1'Auréomycine, réduit le pourcentage de diarrhée sanguinolente de 22 à 3 p. IOO.

HEIDEBRECHT et al. (I950 $a$ et $c$ ) augmentent considérablement le pourcentage de porcelets sevrés en distribuant aux truies en gestation un APF contenant de 1'Auréomycine. Ces truies sont divisées en 3 lots :

- le lot $I$ reçoit une ration de base composée de :

$82 \%$ de maïs jaune ;

I $\%$ de tourteau de soja expeller ;

$5 \%$ de farine de luzerne ;

I,5\% de farine d'os.

- le lot II reçoit cette ration, $+0,5$ p. Ioo d'un APF contenant $27,5 \%$ de vitamine $\mathrm{BI} 2$ par $\mathrm{kg}$.

- le lot $I I I$ reçoit I p. Ioo d'un APF contenant de l'Auréomycine et de la vitamine Br2.

Au cours des expériences, les truies souffrent de troubles digestifs infectieux. Les truies et les porcelets de tous les lots sont atteints de diarrhée. On constate que la diarrhée était beaucoup moins sévère chez les truies et les porcs des lots II et III. L'Auréomycine permit d'augmenter le nombre des porcelets sevrés.

$\begin{array}{cccc}\text { Lot } n^{\circ} & \begin{array}{c}\text { Poids } \\ \text { des porcelets au sevrage }(\mathrm{kg})\end{array} & \begin{array}{c}\text { Pourcentage } \\ \text { de porcs sevrés }\end{array} & \begin{array}{c}\text { Nombre } \\ \text { de porcs sevrés par truie }\end{array} \\ \mathrm{I} & - & - & - \\ 2 & 8, \mathrm{I} & 39,2 & 2,9 \\ 3 & 10,5 & 34,6 & \mathrm{I}, 8 \\ \mathrm{I} 2,4 & 73,4 & 5,9\end{array}$


CARPENTER (I949 a) répartit 24 porcelets pesant de 9 à $23 \mathrm{~kg}$ et tous atteints de diarrhée dir type entérite, en trois lots semblables de 8 porcs chacun. L,e lot I reçoit la ration de base : mais jaune, avoine, issues, tourteau de soja, tankage, farine de luzerne, mélange minéral. Les lots II et III reçoivent cette ration complémentée avec 0,5 et I p. Ioo respectivement d'APF.

Au bout de 4 jours, tous les porcs expérimentaux sauf $\mathrm{r}$ avaient des fèces fermes, les porcs témoins avaient au contraire des fèces sans consistance ou de la diarrhée ;

Le $7^{\mathrm{e}}$ jour, 4 pores témoins et $\mathrm{I}$ porc expérimental avaient la diarrhée. On observa les mêmes résultats à la fin de la $2^{\mathbf{e}}$ semaine, quand on diminua de moitié les quantités d'APF ;

A la fin de l'expérience (fin de la $3^{\mathrm{e}}$ semaine), 2 porcs de contrôle et I porc expérimental avaient la diarrhée. Les gains moyens de poids furent, pour les lots I, 2 et $3: 7$-I I-II, $6 \mathrm{~kg}$ respectivement en 23 jours.

Signalons enfin les travaux de Cufr et al. (I950) sur l'influence des antibiotiques sur 63 porcs chétifs, pesant seulement $9,5 \mathrm{~kg}$ à 72 jours, et ceux de HeIDEBRECHT et al. (I950) sur 42 porcs également chétifs.

Ainsi, cette diminution des diarrhées a pour conséquence une augmentation du pourcentage de porcs sevrés. D'après BRIGGS (I95I), la distribution de $44 \mathrm{mg}$ d'Auréomycine par $\mathrm{kg}$ de ration à des porcelets non sevrés, et 0,5 p. Ioo de supplément de Vitamine Bi2 et d'antibiotiques aux truies pendant la dernière période de la gestation et de la lactation, a permis à l'Institut Hormel d'obtenir, au moment du sevrage, des porcelets pesant 4 à $5 \mathrm{~kg}$ de plus que les animaux témoins.

Il ne faut cependant pas perdre de vue que beaucoup de cas de mortalité des porcelets ont pour cause première des carences nutritionnelles de la mère, et que distribuer une bonne alimentation à la truie avant la naissance des porcelets devrait logiquement précéder l'utilisation des antibiotiques. La présence de "culots de portée " est néanmoins fréquente, et si d'autres résultats venaient confirmer ceux que nous venons de citer, l'emploi des antibiotiques chez ces animaux semblerait, à priori, hautement rentable.

\section{$6^{\circ}$ Besoins en acides aminés et en matières protéiques}

Nous avons vu précédemment qu'on attribuait aux antibiotiques d'autres rôles, qui ont été étudiés ou seulement signalés par différents auteurs :

Augmentation du taux d'hémoglobine du sang (CUNHA, Burnside et al. (I950 $c$ et $d$ ), EDwards, Cunha et al. (I950).

Epargne des besoins en méthionine (CunHa et al. r949 $b$ et $c$ ).

Augmentation de l'efficacité des matières protéiques (CunHA et al. I949 $b$-r95o d). 
Épargne des besoins en vitamine Bi2 (Cunha et al. I950 $b$ ). Épargne des besoins en acide pantothénique (Catron 1952).

Augmentation de l'appétit, du duvet et de la douceur du pelage (Burnside, Cunha et al. I950, Cunha ; Burnside et al. I950 $d$; Cunha et al. I950 $a$ ).

Nous nous arrêterons sur leur intervention dans les besoins en matières azotées :

Cunha et al. (I949 c) distribuent à de jeunes porcelets une ration de base composée de :

$57 \%$ de mais jaune ;

$4 \mathrm{I}, 5 \%$ de tourteau d'arachide ;

I,5\% de matières minérales ;

et supplémentée diversement, comme ci-dessous. Ils obtiennent les gains de poids vifs suivants :

\begin{tabular}{|c|c|c|c|}
\hline Lot $n^{\circ}$ & Supplément à la ration de base & $\begin{array}{l}\text { Poids initial } \\
\text { moyen (kg) }\end{array}$ & $\begin{array}{l}\text { Gain moyen } \\
\text { par jour en g }\end{array}$ \\
\hline 1 & Aucun.............. & 9,5 & 234 \\
\hline 2 & $0,3 \%$ Méthionine & 9,5 & 380 \\
\hline 3 & $2,2 \%$ A.P.F.(1) $\ldots \ldots \ldots \ldots \ldots \ldots \ldots$ & 9,5 & 515 \\
\hline 4 & $0,3 \%$ Méthionine $+2,2 \%$ A. P. I..... & 9,3 & 500 \\
\hline
\end{tabular}

(1) A. P. F. : supplément produit par fermentatio".

La comparaison des gains de poids vif montre que l'addition de 0,3 p. Ioo de méthionine à une ration contenant de l'APF n'apporte aucun bénéfice appréciable, alors que ce bénéfice est très net en l'absence d'APF.

Ce produit agit donc en atténuant les besoins en méthionine du jeune porc. Ceci est en accord avec les résultats obtenus par GiLLIS et NorRIS (I949), qui ont montré, chez le poulet, une action d'épargne de 1'APF à l'égard des composés méthylés, choline et bétaïne en particulier.

Cunha; BuRnside et al. (I950 d), dans des expériences ultérieures, étudièrent l'action de l'APF sur les besoins en matières protéiques du porc. Ils utilisèrent une ration de base composée de maïs et de tourteau

\begin{tabular}{|c|c|c|c|}
\hline Lot $n^{0}$ & $\begin{array}{c}\text { Taux de matières protéiques } \\
\%\end{array}$ & $\begin{array}{l}\text { Poids initial } \\
\text { moyen }(\mathrm{kg})\end{array}$ & $\begin{array}{l}\text { Gain moyen } \\
\text { par jour en } g\end{array}$ \\
\hline $\mathrm{I}$ & 19,6 & 8,6 & 355 \\
\hline 2 & $19,6+\mathrm{APF}$ avec vit. du comp. B & 8,6 & 545 \\
\hline 3 & 17,9 & 8,2 & 324 \\
\hline 4 & $\mathbf{1 7}, 9+\mathbf{A P F}$ & 8,8 & 545 \\
\hline 5 & 15,9 & 8,3 & 288 \\
\hline 6 & $15,9+\mathrm{APF}$ & 8,4 & $44^{1}$ \\
\hline 7 & I 2,2 & 8,7 & 185 \\
\hline 8 & $12,2+\mathrm{APF}$ & 8,8 & 365 \\
\hline 9 & 19,6 & 8,8 & 288 \\
\hline 10 & $19,6+\mathrm{APF}$ & 8,6 & 545 \\
\hline
\end{tabular}

(1) Le supplément APF est " la fraction I " (Stokstad \& Jukes r949a) d'une culture séchée de Sreptomyces aureofaciens, distribuée à la dose de $2,2 \%$. 
d'arachide en proportions variables de sorte que la teneur du régime en matières protéiques varie de 12,2 à 19,6 p. Ioo.

Voir ci-dessus le schéma des rations et les résultats obtenus en 6 semaines :

D'après ces résultats, les auteurs estiment que :

I $^{0}$ Le supplément d'APF a une action d'épargne considérable sur les besoins en matières protéiques du porc, quand la ration ne contient

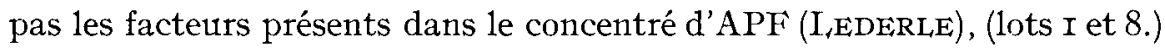

$2^{0}$ Les besoins du porc en matières protéiques peuvent se situer aux environs de I8 p. Ioo si on ajoute de l'APF aux rations (lots 2 et 4 .)

$3^{\circ}$ L'APF stimule la croissance, même quand les vitamines du groupe $B$ ne sont pas ajoutées dans la ration, ce qui est logique, puisque l'APF en lui-même contient déjà une certaine quantité de vitamines B, (lots 9 et 10. )

$4^{0}$ Les besoins en matières protéiques du porc doivent être réévalués en utilisant des quantités adéquates de vitamine $\mathrm{BI} 2$ et d'autres facteurs présents dans les suppléments d'APF.

A la Station expérimentale du Wisconsin, Grummer (I95 I) a obtenu, en utilisant un supplément d'Auréomycine, un abaissement de l'indice de consommation de 5,5-2,5-6,7 p. Ioo avec des régimes à faible, moyenne et forte teneur en protéines.

I'amélioration de la croissance semble relativement constante au cours de ces différentes expériences, quel que soit le taux de matières azotées de la ration. Aussi nous paraît-il, contrairement à l'opinion de STOKSTAD et JukEs (I949 a), que ces résultats tendent à montrer une certaine indépendance des deux actions. RoBIson (I95I), examinant ces résultats, estime également que l'action d'épargne des antibiotiques sur les besoins en protéine est loin d'être démontrée.

Cependant, dans une expérience très détaillée et consacrée à la réévaluation des besoins azotés du porc en fonction de l'emploi des antibiotiques, CATron et al. (I95I) utilisent I 28 porcs de 14 à I $7 \mathrm{~kg}$, groupés en I6 lots et recevant, au début de l'expérience, des rations à 20-I8-I6 et I4 p. Ioo de matières azotées, avec ou sans Auréomycine $(22 \mathrm{mg} / \mathrm{kg}$ de ration). Les auteurs aboutissent aux conclusions suivantes:

Io En l'absence d'antibiotique, les taux optimum de matières azotées sont de I6 p. IOo (jusqu'à $34 \mathrm{~kg}$ ), I3 p. Ioo (de 34 à $68 \mathrm{~kg}$ ) et Io p. Ioo (de 68 à $90 \mathrm{~kg}$ ).

$2^{\circ}$ En présence d'Auréomycine, ces taux sont respectivement de I4, I et 8 p. Ioo. Des taux supérieurs ne donnent pas de meilleurs résultats et, dans ce cas, l'apport de matières azotées excède les besoins du porc, si les rations sont équilibrées de façon à couvrir les besoins des éléments non azotés de la ration.

Ainsi, 1'Auréomycine au taux de $22 \mathrm{mg} / \mathrm{kg}$ de ration semble exercer 
une action épargnante sur les besoins en matières azotées, avec des rations à faible teneur en ces éléments.

Les travaux de BuRNSIDE et al. (I95I) montrent également l'intérêt de 1'Auréomycine avec de faibles taux d'azote : I6-I3-II p. Ioo et I2-IO9,5 p. Ioo, pour les trois périodes suivantes:

- jusqu'à $34 \mathrm{~kg}$;

- de 34 à $57 \mathrm{~kg}$;

- de 57 à $97 \mathrm{~kg}$.

Enfin, Hokfer, L,Uecke et al. (I95I) ont étudié l'action de la Terramycine (I I mg/kg) a vec des rations à $\mathrm{r} 5$ et $\mathrm{r} 8 \mathrm{p}$. Ioo de matières protéiques. Ils aboutissent à des conclusions semblables.

\section{$7^{\circ}$ Action sur la carcasse}

CATRON et a1. (I95I-I952), après avoir étudié 24 carcasses, ne constatèrent aucune action de l'Auréomycine sur l'épaisseur du lard, la longueur, la profondeur et le pourcentage de viande maigre. Ils estiment cependant que l'influence des antibiotiques est mal connue.

BowLAND et al. (I95I) signalent au contraire qu'un APF d'Auréomycine a provoqué : une augmentation du rendement, un renforcement de la couche du lard dorsal et une réduction de la longueur. Mais, en accord avec lui, nous pensons qu'il s'agit vraisemblablement là d'une conséquence directe de l'amélioration de la croissance. Il existe en effet une relation étroite entre la composition du corps de l'animal - en particulier, importance des tissus adipeux - et la vitesse de croissance, comme l'ont montré de nombreux auteurs, dont Mc MEEKan (I940).

Si cette hypothèse était vérifiée, il serait aisé de pallier l'inconvénient signalé par BowI,AND, en supprimant, comme le suggère CATron (I952), la distribution d'antibiotique en fin d'engraissement, pour réduire la vitesse de croissance.

\section{$8^{\circ}$ Action sur l'absorption}

Signalons enfin qu'à la suite de travaux de Catron et al. (I95 I b) sur l'absorption du glucose, il semble que l'Auréomycine :

- diminue la teneur du sang en glucose chez des animaux ayant jeûné avant l'ingestion de glucose,

- augmente cette teneur chez des animaux n'ayant pas jeûné.

\section{b) LA TRUIE GESTANTE ET ALLAITANTE}

CARPenter (I949 $c$, I950 $c$, I95I) a étudié l'effet de l'Auréomycine distribuée à des truies et à leurs porcelets. 
Au cours de ses expériences, le poids des porcelets au sevrage (56 jours) passa de $\mathrm{I} 2 \mathrm{~kg}$ pour le groupe témoin à $\mathrm{I} 7 \mathrm{~kg}$ en distribuant aux truies un régime contenant o,5 p. Ioo d'APF contenant de 1'Auréomycine et aux porcelets, un régime contenant I p. Ioo de ce supplément. Mais la stimulation de croissance ne put être attribuée à aucune substance transportée par le lait ; elle fut causée seulement par 1'Auréomycine incluse dans 1'APF de la nourriture directement ingérée par les porcelets : en effet, les mêmes résultats furent obtenus en ajoutant de l'Auréomycine pure dans leur ration. Par contre, la distribution d'un supplément d'APF contenant de 1'Auréomycine $5^{\circ}$ à 90 jours avant la parturition - ou même pendant toute la gestation - n'a pas modifié l'importance de la portée, ni la taille ou la vigueur des nouveau-nés.

Notons cependant que, d'après HeIDEBrEch'T et al. (I950 c) et Catron (I952), les antibiotiques introduits dans la ration des truies passent dans le lait, où ils sont détectables par les méthodes d'analyse actuelles s'ils sont distribués à des taux égaux ou supérieurs à $22 \mathrm{mg} / \mathrm{kg}$ de ration. Mais, pour BEESON (I95I $a$ et $b$ ) et DoBBINs (I95I), ce passage paraît improbable, ou tout au moins il ne se fait pas en quantités suffisantes pour affecter la croissance ou la santé du porcelet allaité.

Enfin, CARPENTER a montré que si, à partir du sevrage, on réduisait la quantité d'antibiotique dans la ration de porcelets en ayant reçu jusque-1à, on observait une diminution de leur vitesse de croissance et une augmentation de la fréquence des diarrhées. Cette pratique entraîne donc une servitude sérieuse, mais l'importance du problème exige que d'autres travaux permettent de considérer cette conclusion comme entièrement valable.

\section{CONCLUSION}

Malgré le très grand nombre de travaux effectués sur cette question, nos connaissances manquent de précision, et rares sont celles que l'on peut considérer suffisamment sûres. Notıs pouvons cependant, avec BEESON (I95I $a$ ) et CATRON (I95I, I952), dresser la liste des conclusions pouvant, à l'heure actuelle, être considérées comme valables.

\section{Choix et mode d'emploi des antibiotiques}

Io Les antibiotiques qui peuvent stimuler la croissance du porc sont très nombreux ; citons 1'Auréomycine, 1a Streptomycine, la Pénicilline, la Terramycine, la Bacitracine. Mais les antibiotiques " de choix " pour le porc sont 1'Auréomycine et la Terramycine. La Pénicilline ne s'est pas révélée aussi efficace pour favoriser la croissance. 
$2^{\circ}$ Le taux optimum courant et efficace de distribution de ces antibiotiques est approximativement de II $\mathrm{mg} / \mathrm{kg}$ de ration $(5 \mathrm{mg} / \mathrm{lb})$. Ce taux ne correspond qu'au $\mathrm{I} / 30^{\mathrm{e}}$ ou $\mathrm{I} / 5 \mathrm{O}^{\mathrm{e}}$ des doses thérapeutiques utilisées pour le traitement des affections microbiennes.

Cependant, BeEson insiste sur le fait que le taux d'antibiotique exigé pour assurer une croissance maxima varie avec l'antibiotique, l'individı, le milieu et le régime.

$3^{\circ}$ Les antibiotiques sont efficaces chez les porcs, qu'ils soient ou non élevés au pâturage.

$4^{\circ}$ On n'a pas suffisamment étudié la question des combinaisons d'antibiotiques. On ne sait pas si elles sont plus efficaces ou moins efficaces qu'un seul antibiotique " de choix " distribué au même taux.

$5^{\circ} \mathrm{La}$ Terramycine, 1'Auréomycine et la Pénicilline sont assez stables dans les aliments, quand on les stocke pendant une durée normale.

$6^{\circ}$ Les antibiotiques ne remplacent ni des rations bien équilibrées, ni l'hygiène, ni le contrôle des maladies. On peut les employer pour améliorer la nutrition de l'animal, mais non comme produits de remplacement.

\section{Consommation et indice de consommation}

$7^{\circ}$ I.es antibiotiques accroissent la consommation journaliere d'aliments de Io $\grave{a} 20 \mathrm{p}$. Ioo.

$8^{\circ}$ Ils abaissent de 5 à Io p. Ioo l'indice de consommation obtenu dans les conditions normales d'alimentation. (Cf. figure 2).

$9^{\circ}$ Les porcs recevant des antibiotiques boivent davantage.

\section{Croissance}

Io $0^{\circ}$ Ils augmentent la vitesse de croissance de ro à $20 \mathrm{p}$. Ioo depuis le sevrage jusqu'au poids de $90 \mathrm{~kg}(200 \mathrm{lb})$, dans les conditions normales d'alimentation. D'après BEESON (I95I $a$ ), cette augmentation des gains de poids vif atteint $\mathrm{I} 80 \mathrm{~g}$ par jour environ, soit $\mathrm{I} 8 \mathrm{~kg}$ en plus en roo jours. (Cf. figure 2).

II $^{\circ}$ La réponse de croissance maxima est obtenue quand on les distribue à de jeunes porcs : les augmentations de gains sont moindres après $45 \mathrm{~kg}$. Il est donc recommandé de donner les antibiotiques à partir du moment où le jeune porc commence à manger $\left(2^{\mathrm{e}}\right.$ semaine $)$, mais il est indispensable de continuer jusqu'à l'abattage (BEESON I95I $b$ ).

I $2^{\circ} \mathrm{La}$ réponse à la distribution d'antibiotiques semble être directement proportionnelle au taux de maladie (" disease level "). Dans certains cas, des porcs qui paraissaient en bonne santé n'ont pas réagi aux antibiotiques. 


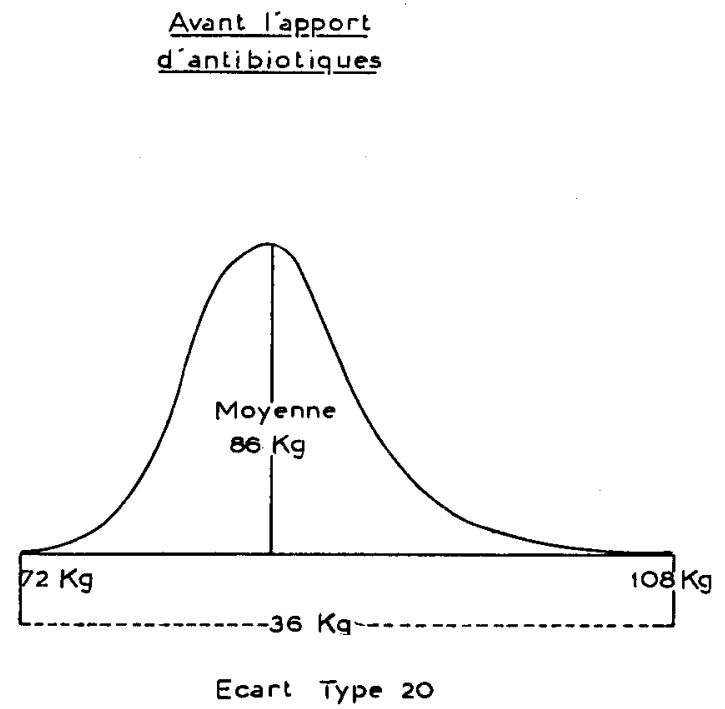

\section{Avec Antibioliques}

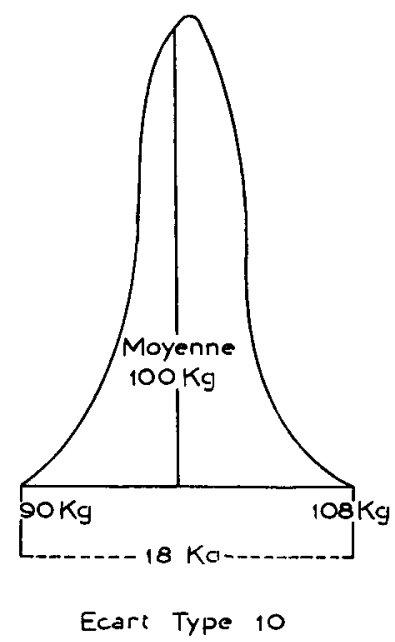

Les Antibiotiques réduisent les Variations de poids entre les Porcs d'une même Portée Poids a 5 Mois

FIG. I.

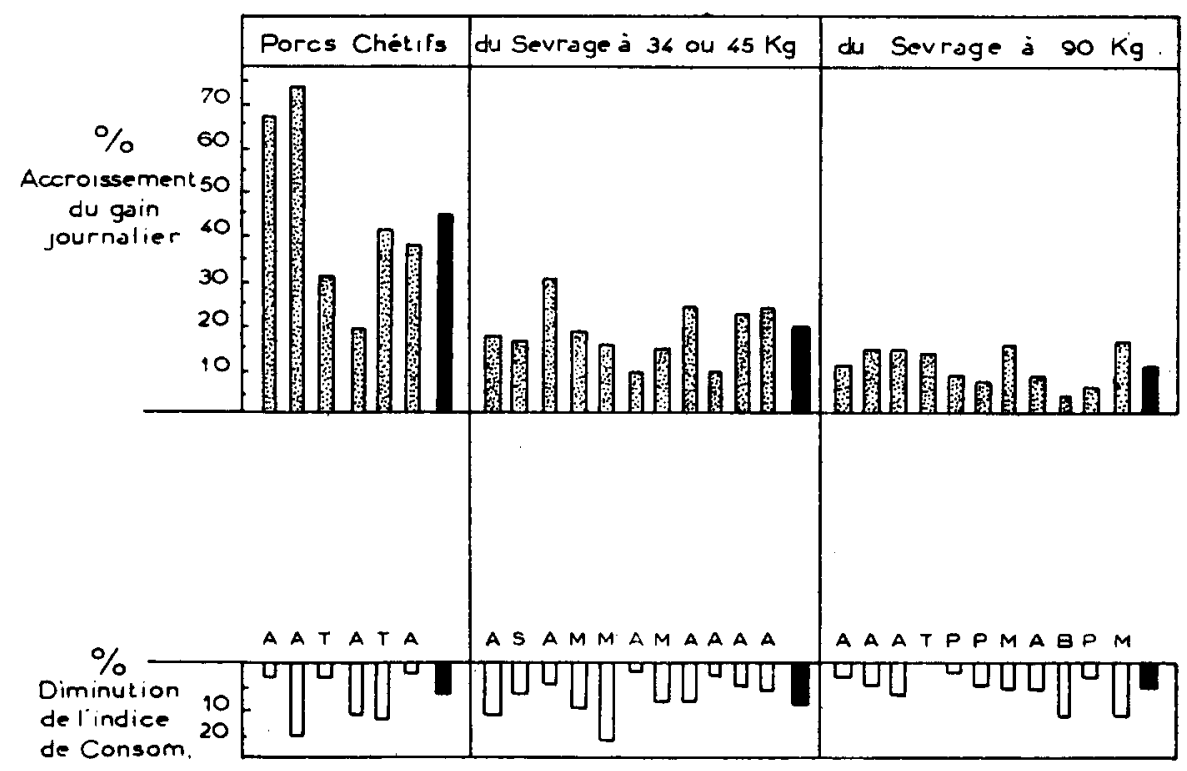

$$
\begin{array}{lll}
A=\text { Auriomycine } & T=\text { Terramycine } & S \text {-Streptomycine } \\
B=\text { Bacitracine } & M=\text { Mélange } & \text { P-Pénicilline }
\end{array}
$$

Effet d'apports dantibiotiques dans lalimentation du Pore

Résumé de 21 Expériences comportant 1068 Porcs

FIG. 2. 
I $3^{\circ}$ Les antibiotiques tendent à unifier la croissance d'un groupe de porcs et facilitent l'obtention d'un poids plus uniforme, en évitant la présence des "culots" (cf. figure I), CATRON (I952).

$\mathrm{I}_{4}{ }^{\circ}$ Les porcelets allaités qui reçoivent des antibiotiques " de choix") pèsent de 2,2 à $5 \mathrm{~kg}$ de plus par porc au sevrage ( 8 semaines).

$5^{\circ}$ Les porcs de plus de $56 \mathrm{~kg}$ à qui on retire les antibiotiques de leur ration ont des gains de poids plus lents que ceux qui en reçoivent d'une façon continue jusqu'à l'abattage.

\section{Antibiotiques aux truies}

I6 La distribution d'antibiotiques à des truies gestantes ne peut influencer le poids du porcelet à la naissance, sa force, sa vitalité ou sa résistance aux maladies. I es antibiotiques ne présentent donc pas d'intérêt dans les rations des truies gestantes et allaitantes (BEESON I95 I a et b)-(DobBINs I95I).

CATRON au contraire est moins catégorique : "On n'a pas suffisamment étudié l'importance de la distribution d'antibiotiques aux truies pendant la gestation et la lactation. "

\section{Actions diverses}

I $7^{\circ}$ I,es antibiotiques produisent deux sortes d'effets indépendants ou simultanés:

- contrôle des affections gastro-intestinales, en particulier des entérites non spécifiques du porc,

- action d'épargne ou de synthèse, ou les deux à la fois.

I $8^{\circ}$ La distribution d'antibiotiques semble "épargner" de l'énergie, des protéines et certaines vitamines hydrosolubles.

I9 ${ }^{\circ}$ Un type inconnu de dermatite des porcs a été guéri par absorption orale d'un antibiotique " de choix".

$2^{\circ}$ Les porcs recevant des antibiotiques présentent des foies exceptionnels par leur parfait état.

$2 \mathrm{I}^{\circ}$ L'action des antibiotiques sur la qualité de la carcasse n'est pas complètement connue. Ils peuvent accroître la proportion de graisse si on les distribue sans discontinuer jusqu'au poids d'abattage.

$2^{\circ}$ L'emploi des antibiotiques dans l'alimentation ne semble pas, jusqu'à présent, avoir provoqué une résistance ou une accoutumance à leur action, de nature à réduire l'ampleur de leurs effets. 


\section{VI. - ÉTUde DES ANTIBIOTIQUES CHEZ LES RUMINANTS}

\section{a. - LE VEAU}

I,e veau se comportant, dans la première partie de son existence, comme un monogastrique, il n'est pas étonnant d'observer que ses réponses à l'addition d'antibiotiques dans sa ration sont voisines de celles du porc.

LoosLi et al. (I95I) indiquent que 4 groupes différents de chercheurs ont montré que 1'Auréomycine agissait favorablement sur la croissance, l'indice de consommation, la fréquence et la gravité des diarrhées et, d'une façon générale, sur l'aspect général de l’animal.

\section{$I^{0}$ Action sur la croissance}

D'expériences effectuées à Cornell par I,oosLI et a1. (I95o b), sur des veaux pris à la naissance et élevés jusqu'à I6 semaines, il résulte que l'action des antibiotiques sur la croissance se fait particulièrement sentir pendant les huit premières semaines. Les auteurs ajoutent 2 p. Ioo d'un supplément d'antibiotique I,EDERLE, soit au lait, soit à l'aliment de remplacement. Ils disposent de 40 paires de veaux pendant les 8 premières semaines, et $\mathrm{I} 2$ paires de $1 \mathrm{a} 9^{\mathrm{e}}$ à la $\mathrm{I} 6^{\mathbf{e}}$ semaine. Les différences de croissance dues aux antibiotiques furent significatives et de l'ordre de 8 à ro p. Ioo. Voici les résultats obtenus :

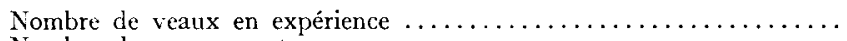

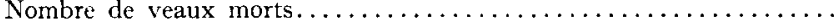

Gain journalier moyen (en grammes) :

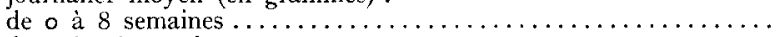

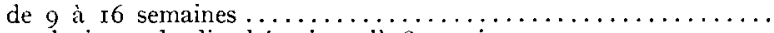

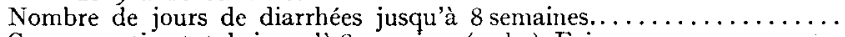

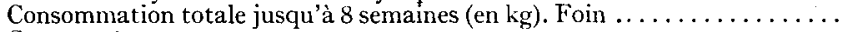

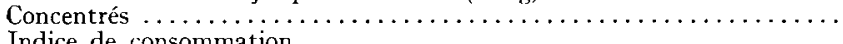

$\begin{array}{cc}\begin{array}{c}\text { Lot } \\ \text { témoin }\end{array} & \begin{array}{c}\text { Lot } \\ \text { antihiotique }\end{array} \\ 40 & - \\ \text { I } & 40 \\ & 0 \\ 426 & 522 \\ 744 & 739 \\ 10,0 & 3,8 \\ 8,7 & 7,2 \\ 29,7 & 38,7 \\ 2,85 & 2,53\end{array}$

On voit que de 9 à $\mathrm{I} 6$ semaines, les gains de poids furent pratiquement identiques dans les deux groupes.

RUSOFF, DAVIS et AlFord (I950-I95I) ajoutent de 1'Auréomycine à des farines pour veaux (starters) ne contenant pas de protéines animales. Ils disposent de 3 groupes de 8 veaux mâles de race pure (4 Jersey et 4 Holstein par groupe).

Le Groupe I ou groupe témoin, reçoit la ration de base (starter + lait).

Le groupe $I I$ reçoit 2 p. Ioo d'un supplément dosant 2,5 g d'Auréomycine par $\mathrm{kg}$ ajouté au starter, qui est distribué à partir du $7^{\mathrm{e}}$ jour 
d'âge. Les veaux sont sevrés à 30 jours et reçoivent alors le starter ad libitum.

Le groupe III reçoit la même ration de base, avec $75 \mathrm{mg}$ d'Auréomycine $\mathrm{HCl}$ cristallisée en capsule par jour, à partir $\mathrm{du} \mathrm{I}_{4} \mathrm{e}$ jour d'âge, jusqu'à la $\mathrm{I}^{\mathrm{e}}$ semaine, et $\mathrm{I}_{5} \mathrm{O} \mathrm{mg}$ pendant les 6 dernières semaines.

Voici les résultats obtenus pendant go jours, avec 2 races de veaux :

\begin{tabular}{|c|c|c|c|}
\hline & Lot I & Lot II & Lot III \\
\hline 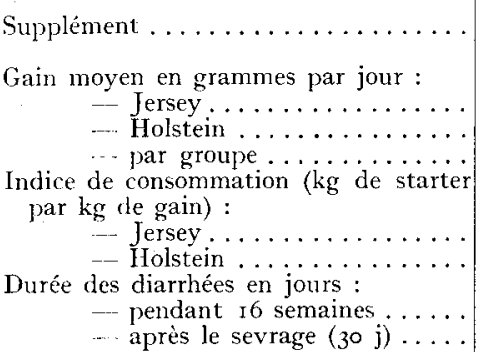 & $\begin{array}{l}\text { Aucun } \\
\\
449 \\
635 \\
540 \\
\\
2,47 \\
2,32 \\
2,5 \\
2,0\end{array}$ & $\begin{array}{l}\text { Auréomycine } \\
\text { (supplément) } \\
\\
549 \\
767 \\
658 \\
\\
2,64 \\
2,07 \\
2,0 \\
0,6\end{array}$ & $\begin{array}{l}\text { Auréomycine } \mathrm{HCl} \\
\text { cristallisée } \\
\\
581 \\
730 \\
653 \\
\\
2,44 \\
2, \mathrm{I} 6 \\
-\end{array}$ \\
\hline
\end{tabular}

On voit que 1'augmentation de croissance due aux antibiotiques fut d'environ 25 p. Ioo pour les veaux Jersey, I5 p. Ioo pour les veaux Holstein.

Il y eut également diminution des diarrhées.

Signalons également les travaux de Morrison et al. (I95I) et MurLEY et a1. (I95I), réalisés respectivement avec des gétnisses nourries au lait entier et des veaux mâles nourris de lait reconstitué. MurLEY et al. constatent que l'action de l'Auréomycine est plus nette quand on ajoute au régime lacté des céréales et du foin.

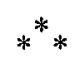

Des expériences très intéressantes ont été réalisées par BARTLEY et FoUNTAINE (I950-I95I), pour étudier l'action des antibiotiques au moment où le rumen commence à fonctionner. Ils disposent de 24 veaux de quatre races différentes, répartis en 3 groupes de 8 :

Le groupe $I$ ne reçoit aucun supplément.

Le groupe II reçoit un concentré d'APF contenant de 1'Auréomycine résiduelle $(5 \mathrm{mg} / \mathrm{g})$, cet $\mathrm{APF}$ est distribué chaque jour en capsules, au taux de $6,6 \mathrm{~g}$ par Ion $\mathrm{kg}$ de poids vif, soig $33 \mathrm{mg}$ d'Auréomycine, de la naissance à 7 semaines.

Le groupe III reçoit le même régime que le groupe II, mais pendant les douze premières semaines. 
La ration de base pour tous les veaux est la suivante:

de la naissance à 3 jours inclus.............

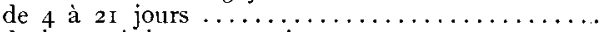
de la $\mathrm{I}^{\mathrm{re}}$ à la $\mathrm{I}^{\mathrm{e}}$ semaine $\ldots \ldots \ldots \ldots \ldots \ldots \ldots \ldots \ldots$

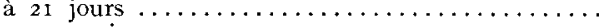
$\mathrm{r}^{\mathrm{e}}$ semaine $\ldots \ldots \ldots \ldots \ldots \ldots \ldots \ldots \ldots \ldots \ldots \ldots$ colostrum,

lait entier: I $\mathrm{kg}$ par Io $\mathrm{kg}$ de poids vif, foin et grain,

substitution progressive de lait écrémé, lait écrémé : I $\mathrm{kg}$ par to $\mathrm{kg}$ de poids vif.

$A u$ bout de 42 jours, les veaux expérimentaux ont gagné en moyenne $I_{4}, 0 \mathrm{~kg}$, et les veaux témoins, $8,2 \mathrm{~kg}$.

Ces croissances sont très faibles par rapport aux standards de RAGsDALE -- déjà modestes - puisque, d'après leur race et leur sexe, les veaux auraient dî gagner respectivement I4,o et I4,5 kg. Ce fait est dû aux diarrhées qui ont été considérables dans le lot témoin. Au contraire, l'Auréomycine a réduit l'incidence des diarrhées et, par là même, augmenté la croissance.

De la $7 \mathrm{e}$ à la $12^{\mathrm{e}}$ semaine, les auteurs notent:

- que le groupe III présente des gains rapides ;

- que le groupe II a une vitesse de croissance ralentie.

D'après ces auteurs, ces résultats sont importants, parce que l'augmentation de croissance notée de la $7^{\mathrm{e}}$ à la $\mathrm{I} 2^{\mathrm{e}}$ semaine, due sans aucun doute à l'Auréomycine, a été obtenue "alors que le rumen fonctionnait apparemment d'une façon normale ». De plus, cette augmentation a été plus grande que celle obtenue plus tôt, quand le veau n'était pas encore ruminant.

A partir de la 12e semaine, quelques animaux ont continué à recevoir la même dose d'antibiotique ( $33 \mathrm{mg}$ par $100 \mathrm{~kg}$ de poids vif), jusqu'à la $2 \mathrm{O}^{\mathrm{e}}$ semaine, sans effets nocits. D'autres veaux ont reçu dans les mêmes conditions une dose trois fois plus forte, également sans inconvénients. Par contre, un seul animal ayant reçu $66 \mathrm{mg}$ d'antibiotique (pour roo $\mathrm{kg}$ de poids vif) présenta à la $15^{\mathrm{e}}$ semaine, une perte de poids et d'appétit.

Enfin, on doit noter que l'Auréomycine a augmenté sensiblement la consommation de nourriture et que les indices de consommation (protéiques) furent sensiblement réduits pour le groupe II, comme le montrent les résultats suivants :

Indice de consommation protéique

\begin{tabular}{|c|c|c|c|}
\hline Groupes & I & II & \\
\hline $\begin{array}{l}\text { Ourée de la supplémentation } \ldots \ldots \ldots \ldots \ldots \ldots \ldots \ldots \ldots \ldots \ldots \ldots \ldots \\
\text { Taissance à } 7 \text { semaines } \ldots \ldots \ldots \ldots \ldots \ldots \ldots\end{array}$ & $\begin{array}{c}0-7 \text { sem. } \\
0,41\end{array}$ & $\begin{array}{l}\underset{0-12 \mathrm{sem}}{0,39} \\
0,\end{array}$ & \\
\hline 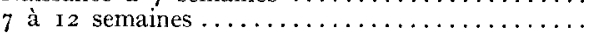 & 0,63 & $0,4 \mathrm{I}$ & 0,48 \\
\hline
\end{tabular}

L'action de 1'Auréomycine sur les jeunes ruminants semble bien être favorable jusqu'à la $\mathrm{I}^{\mathrm{e}}$ semaine.

JACOBSON et al. (I95I) utilisent 26 veaux, pendant plus de 28 semaines. Ils les divisent en deux groupes semblables, nourris du $4^{\mathrm{e}}$ au $\mathrm{II}^{\mathrm{e}}$ jourr d'âge, de lait, foin et grains. Le groupe expérimental reçoit en plus une dose journalière de $80 \mathrm{mg}$ d'Auréomycine cristallisée 
par veau, administrée dans le lait. La différence de poids moyen entre le groupe de contrôle et le groupe expérimental, déjà sensible à 32 jours (4 kg), atteint I9 $\mathrm{kg}$ à 116 jours, soit une augmentation de 2I p. IOO.

Poids moyen des veaux $(k g)$

\begin{tabular}{|c|c|c|c|c|c|}
\hline Jours ............ & 4 & $3^{2}$ & 60 & 88 & II 6 \\
\hline Groupe contrôle $\ldots . .$. & $\begin{array}{l}30,4 \\
30,8\end{array}$ & 38,6 & 53,5 & 69,9 & 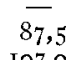 \\
\hline
\end{tabular}

A II6 jours, la distribution de lait et d'Auréomycine $\mathrm{HCl}$ cristallisée est arrêtée. On utilise alors un supplément alimentaire (Aurofac A, LEDERLE) contenant de l'Auréomycine, que l'on distribue dans le concentré. Mais on divise chacun des deux groupes en detux lots, la moitié environ du groupe de contrôle recevant de l'Auréomycine et la moitié du groupe expérimental n'en recevant plus. On continue ainsi l'expérience jusqu'à 200 jours. A ce moment, on note que :

I $^{\circ}$ L,es animaux qui ont reçu de l'Auréomycine sans discontinuer de 4 à 200 jours, aux doses de 80 à $240 \mathrm{mg}$ par jour, ont gagné $30 \mathrm{p}$. 100 de plus que ceux qui n'en ont jamais reçu et dont la croissance est voisine des standards de croissance de RAGSDALE;

$2^{\circ}$ L'introduction d'Auréomycine dans le concentré pour la première fois à II 6 jours, à la dose de $80 \mathrm{mg}$ par jour, n'a pas ent, en général, d'effets nuisibles ;

$3^{\circ}$ La suppression d'Auréomycine dans le régime à II6 jours, ne provoque pas non plus d'effets nuisibles.

Il peut paraître étrange que l'action favorable de l'Auréomycine se prolonge aussi longtemps, alors que HuHTANEM (I95I) a montré que c'est vers 1'âge de 2 mois que se produit, chez le veau, la modification de la flore microbienne du rumen et que, comme nous le verrons plus loin, les antibiotiques provoquent des effets défavorables chez les ruminants adultes.

L'hypothèse de l'intervention des microorganismes du tube digestif dans l'action des antibiotiques ne rend pas compte de cette observation, et ce point mérite certainement de faire l'objet de nombreuses études.

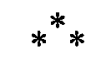

Alors que l'Auréomycine semble toujours améliorer la croissance, la Terramycine, elle, provoque des effets variables.

VOFLKER et CASON (I95I), distribuant $66 \mathrm{mg}$ de Terramycine par $\mathrm{kg}$ de poids vif, observent une amélioration de la croissance des veaux traités au cours de deux expériences.

MURDock (I95I), au contraire, note: "La Terramycine s'est révélée inefficace pour accroitre les gains de poids ou pour améliorer la santé ou 
l'aspect général des veaux âgés de I2 semaines au plus. Au contraire, on a noté chez les veaux recevant de la Terramycine jusqu'à la $6^{\mathrm{e}}$ semaine, une baisse du taux de croissance de $1 \mathrm{a} 6^{\mathrm{e}}$ à $1 \mathrm{a} \mathrm{I} 2^{\mathrm{e}}$ semaine. Les différents résultats obtenus par plusieurs chercheurs peuvent être en relation avec les différentes méthodes d'alimentation ou d'élevage ".

On voit que les résultats obtenus avec un antibiotique quelconque sont divergents et souvent inexpliqués. Aussi Werner (I95I), dans une revue des différents travaux réalisés sur ce sujet, conclut-il : "Il faut encore travailler beaucoup avant que l'on puisse répondre à toutes les questions concernant la distribution d'antibiotiques aux jeunes veaux ou aux ruminants plus âgés... Si par exemple l'antibiotique est ingéré de façon à ce qu'il évite le rumen, agira-t-il autrement que si il l'atteint ? "

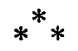

En plus de leur action sur la croissance, les antibiotiques augmentent en général l'appétit des veaux pour les concentrés et diminuent l'indice de consommation. (BARTLEY et FountaINe (I950-I95I). En fait, cette diminution de l'indice de consommation est loin d'avoir le caractère général de l'augmentation de croissance. Elle est parfois faible, sinon nulle, et n'est pas toujours significative, comme nous l'avons vu notamment dans les expériences de Rrsofr et al. (I950-I95I),

D'après I 00 SLI (I95I), les autres antibiotiques qui sont efficaces pour les volailles et les porcs n'ont pas été expérimentés pour les veaux d'élevage.

\section{$2^{\circ}$ Action sur les diarrhées}

D'après les chercheurs du Laboratoire LEDERLE, les diarrhées que l'on observe chez les veaux depuis l'âge de Iz heures jusqu'à quelques mois peuvent être enrayées par l'addition de petites quantités d'Auréomycine au régime. Ainsi, de récents essais effectués au Collège d'Etat de Pensylvanie (Anonyme 195I) ont montré que, sur 53 veaux atteints de diarrhée, $f^{6}$ furent guéris avec de 1'Auréomycine, 5 virent leur état de santé s'améliorer, 2 seulement moururent. L,es auteurs concluent que l'Auréomycine, à cet égard, est plus efficace que n'importe quelle combinaison de produits soufrés (sulfamides). Ces résultats sont en accord avec ceux de Rusoff et Davis (I950-I95I), Rusoff, DAvis et AlFord (I95I), I,OOSLI et WALLACE (I950 a), LoOsLI et al. (I950 b), BARTLEY et FountaINe (I950-I95I), que nous avons cités au paragraphe précédent, et WerNer (r95I).

Mais, à propos de leur emploi, BARTLEY (I95I) fait justement remarquer que c'est surtout dans le premier âge que la diarrhée provoque de 
graves accidents. Or, les antibiotiques sont généralement inclus dans l'aliment "starter " distribué à partir de 3 semaines, c'est-à-dire trop tard pour agir sur les cas les plus fréquents.

\section{$3^{\circ}$ Doses utilisées}

Nous ne pouvons pas donner ici les doses optima à utiliser puisqu'il semble bien qu'ancune étude systématique n'ait été faite pour les déterminer, dans le cas de chaque antibiotique. Nous nous contentons de donner quelques chiffres utilisés dans plusieurs expériences, pour montrer leur variation et, si possible, fixer les idées sur un ordre de grandeur :

Dose par jour :

75 à I50 mg d'Auréomycine (RUSOFF I95O-I95I).

80 à $240 \mathrm{mg}$ d'Auréomycine (JACOBSon et al. I95I).

$2500 \mathrm{mg}$ d'Auréomycine $\mathrm{HCl}$ cristallisée (BARTLEY et al. I95I).

Dose par kg de ration:

$50 \mathrm{mg}$ d'Auréomycine, soit 2 p. Ioo d'un supplément dosant 2,5 mg d'Auréomycine cristallisée par kg (RUSOFF et al. I95I).

IIo $\mathrm{mg}$ d'Auréomycine par $\mathrm{kg}$ de starter, soit $2 \mathrm{p}$. Ioo d'un supplément dosant $2,5 \mathrm{mg}$ d'Auréomycine par $\mathrm{lb}$ (Rusoff et al. I95I).

Ioo $\mathrm{mg}$ par $\mathrm{kg}$ de grains, soit 2,5 p. Ioo d'APF à $4 \mathrm{mg}$ d'Auréomycine par $\mathrm{g}+200 \mathrm{mg}$ d'Auréomycine pure (VOELKER et al. I95I).

Dose par Ioo $\mathrm{kg}$ de poids vit :

33 à $66 \mathrm{mg}$ d'Auréomycine, soit 6,6 et I3,2 d'un supplément APF contenant $5 \mathrm{mg}$ d'Auréomycine résiduelle par $\mathrm{g}$ (BAR'TLEY et al. I950).

33 à $66 \mathrm{mg}$ de Terramycine (Uté d'Arkansas, d'après Werner I95I).

66 et $220 \mathrm{mg}$ de Terramycine (VOFLKER et al. I95I).

440 à I $760 \mathrm{mg}$ d'Auréomycine $\mathrm{HCl}$ (BARTLEY et al. I95I).

\section{b. - LES BOVINS ADULTES}

La plupart des auteurs notamment LoOSLI (I95I), WERNER (I95'I), BARTLEY (I95I), considèrent que les antibiotiques ont une action nuisible sur la croissance des bovins adultes. Ils expliquent ce phénomène par leur influence sur les microorganismes du rumen qui, on le sait, jouent un rôle considérable dans la digestion chez les ruminants.

BELL, et a1. (I950-I95I) ont étudié l'action de l'Auréomycine cris- 
tallisée sur la digestion et la rétention azotée de six bouvillons. La ration de base est composée de maïs, tourteau de soja, foin de pré. 2 animaux reçoivent cette ration supplémentée avec de l'urée. Les coefficients de digestibilité pour ces deux types de rations ont été obtenus dans des expériences précédentes, avec des bœufs ne recevant pas d'Auréomycine. Les 6 bœufs reçoivent en plus de la ration de base, avec ou sans urée, $600 \mathrm{mg}$ d'Auréomycine par jour.

Le schéma de l'expérience est donc le suivant :

\begin{tabular}{cccc} 
Nombre de boufs & Ration de base & Urée & Auréomycine \\
\hline 4 & - & - & - \\
2 & + & - & $600 \mathrm{mg}$ \\
& + & + & $600 \mathrm{mg}$
\end{tabular}

Dans les 2 à 3 jours qui suivirent l'ingestion d'Auréomycine, les auteurs notent une anorexie accusée et de la diarrhée. Plus tard, en distribuant 2 oo mg d'Auréomycine, ils constatent une baisse du coefficient de digestibilité apparente de $15 \mathrm{p}$. Ioo pour la matière sèche, et $50 \mathrm{p}$. Ioo pour les matières cellulosiques. Ils expliquent ce résultat par l'inhibition du travail de dégradation des matières cellulosiques habituellement effectué par les microorganismes, dont l'activité se trouve bloquée par les antibiotiques.

Au contraire, d'autres auteurs ne constatent pas d'effets nuisibles, tels BAR'TLEY et al. (I950), qui utilisent des doses journalières de I $760 \mathrm{mg}$ par IOo kg de poids vif, sur des bouvillons de 3-4 mois ; FERGUSON (I95I), qui distribue I $000 \mathrm{mg}$ d'Auréomycine à des génisses de 4 mois, alors qu'il constate une perte d'appétit après l'ingestion de $75^{\circ} \mathrm{mg}$ d'Auréomycine par des bouvillons de $300 \mathrm{~kg}$; RUSOFF (I95I), utilisant la dose de $50 \mathrm{~g}$ d'Auréomycine par $\mathrm{kg}$ de ration, avec des génisses de 3 mois $\mathrm{r} / 2$.

Cependant, et d'une façon générale, malgré les résultats apparemment contradictoires de ces différentes expériences, il semble bien que les doses supérieures à $200 \mathrm{mg}$ provoquent des effets nuisibles chez les bovins adultes, et nous dirons avec LoOSLI (I95I) : " D'autres études effectuées sur des ruminants de tous les âges sont nécessaires avant qu'il soit possible d'évaluer définitivement le rôle bénéfique ou nuisible des antibiotiques".

\section{c. - LES OVINS}

D'après LoosLi (I95I), un certain nombre de travaux ont montré que les antibiotiques pouvaient être également nuisibles pour les moutons.

Colby et al. (I950 a) comparent l'influence de l'Auréomycine, de la Pénicilline et de la Streptomycine sur l'engraissement des agneaux. Au bout de I4 jours d'expérience, l'addition de roo $\mathrm{mg}$ d'Auréomycine par jour provoque chez les animaux un dédain presque total de leurs aliments 
et une perte de poids de 75 et go $g$ pour les deux lots de 6 agneaux, alors que les six agneaux témoins ont gagné $235 \mathrm{~g}$ par jour.

Dans deux autres essais, ils utilisent les mêmes doses de Streptomycine et de Pénicilline (ingestion en capsules), avec 3 groupes de 7 agneaux. La Pénicilline provoque un dédain des rations, une perte de poids et des diarrhées pendant plusieurs jours. Puis les animaux revinrent graduellement à leur état normal, mais à la fin de l'expérience, le poids de ce lot était encore inférieur à celui du lot témoin.

I a Streptomycine fut le moins actif des trois antibiotiques. Les gains de poids du lot traité furent légèrement moindres que ceux du groupe témoin.

Dans une autre expérience, ColBy et al. (1950 b) utilisent 5 I agneaux âgés de 4 à $\mathrm{I} 2$ semaines (moyenne 7 semaines environ), atteignant des poids variant entre 3,4 et $30,8 \mathrm{~kg}$. Ils sont divisés an hasard en deux lots :

- le lot $I$ reçoit la ration de base composée d'avoine, de milo. de son, de tourteau de coton et de foin de luzerne ad libitum ;

- le lot II reçoit la même ration additionnée de I p. Ioo (pendant 2 semaines), puis $0,5 \mathrm{p}$. Ioo d'un supplément d'APF contenant, par $\mathrm{g}$ o,6 microg de vitamine $\mathrm{BI} 2$ et $4 \mathrm{mg}$ d'Auréonycine, soit des doses de :

40 et $20 \mathrm{mg}$ d'Auréomycine.

6 et $3 \%$ de vitamine Bı2 par $\mathrm{kg}$ de ration.

Au bout de 56 jours, tous les agneaux sont sevrés, et l'expérience continue encore pendant 28 jours. On constate que la distribution d'Auréomycine diminue la vitesse de croissance et la consommation de nourriture des agneaux, par rapport au lot témoin. Il faut noter que cette influence nuisible ne se manifeste qu'après le sevrage (gain par jour, ıoo g au lieu de $\mathrm{I} 72 \mathrm{~g}$ ) : sans doute le lait maternel a-t-il une action protectrice. Par ailleurs, les agneaux supplémentés ont produit des fibres de laine de longueur légèrement plus réduite et de diamètre légèrement plus petit. Lateneur du sang et des tissus en vitamine $\mathrm{BI} 2$, chez les animaux recevant de l'APF, était significativement plus faible au sevrage et après.

Enfin, dans une $3^{\mathrm{e}}$ expérience réalisée avec des agneaux, Col.BY et al. (I95I) notent une perte d'appétit notable, entraînant des pertes de poids importantes.

Les auteurs disposent de $\mathrm{I} 8$ agneaux de races diverses, pesant en moyenne $26 \mathrm{~kg}$ et répartis en 3 lots de 6 animaux :

- le lot I reçoit une ration de base composée de :

$90 \%$ de milo,

Io $\%$ de tourteau de coton, avec du foin de luzerne ad libitum,

- le lot II reçoit cette ration supplémentée par un concentré d'Auréomycine brute, en quantité suffisante pour apporter Ioo $\mathrm{mg}$ d'Auréomycine pure par jour, 
- le lot III reçoit la même ration que le lot II, plus un certain nombre de vitamines $B$ : thiamine, riboflavine, niacine, acide pantothénique, pyridoxine, choline, biotine, acide folique, acide p. aminobenzoïque, inositol.

On distribue en plus à ces agneaux, un mélange de vitamine BI2 et BI2 $b$, au taux de $20 \%$ par jour et par animal.

Voici les résultats obtenus au bout des I4 jours d'expérience : " L'expérience fut de courte durée, parce que les deux groupes d'agneaux qui recevaient l'Auréomycine perdirent du poids si rapidement qu'on décida d'arrêter les essais plutôt que de sacrifier les animaux ».

Action de l'Auréomycine sur la croissance et sur la consommation de nourriture

\begin{tabular}{|c|c|c|c|}
\hline Lot $n^{\circ}$ & I & II & III \\
\hline 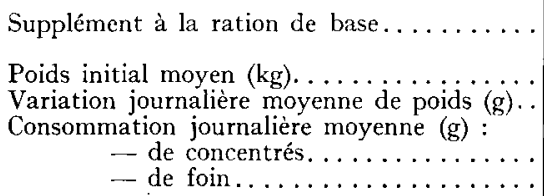 & $\begin{array}{l}\text { Aucun } \\
\begin{array}{r}24,8 \\
+ \\
+236 \\
680 \\
567\end{array}\end{array}$ & $\begin{array}{l}\text { Auréomycine } \\
\qquad \begin{array}{c}26,4 \\
-73 \\
45 \\
9 \mathrm{I}\end{array}\end{array}$ & $\begin{array}{c}\text { Auréomycine } \\
\text { Vitamines B } \\
\quad 26,6 \\
-91 \\
45 \\
82\end{array}$ \\
\hline
\end{tabular}

Par ailleurs, l'étude du rumen a montré que chez les animaux ayant reçu de l'Auréomycine et des vitamines du complexe $B$, les aliments étaient très divisés, tout à fait liquides, indiquant un séjour trop prolongé dans le rumen et un fonctionnement anormal de celui-ci. On ne peut donc pas supposer que l'action nuisible de l'Auréomycine ait pour origine une carence en vitamines $B$ normalement fournies à l'animal par synthèse bactérienne, puisque l'apport de ces vitamines dans la ration n'a aucun effet bénéfique.

D'après les auteurs, l'Auréomycine détruit probablement les lignées de bactéries qui sont nécessaires au rumen pour la digestion des aliments, et son fonctionnement normal. De ce fait, l'Auréomycine, diminuant la concurrence vitale, permettrait à d'autres lignées moins désirables de se développer plus rapidement. Ainsi :

- chez les animaux témoins (lot $I$ ), le rumen était développé, bien rempli d'aliments d'apparence normale, et on y dénombrait de $500000 \dot{a}$ 750000 bactéries par $\mathrm{g}$ de contenu,

- chez les animaux recevant de l'Auréomycine seule (lot II), le rumen était plus petit et renfermait beaucoup moins d'aliments. Le contenu était cependant d'apparence normale, mais le taux de bactéries était beaucoup plus élevé et situé entre 8 et 22 millions par $\mathrm{g}$ de contenu,

- enfin, les animaux recevant de l'Auréomycine et des vitamines 
$\mathrm{du}$ groupe B (lot $I I I)$ avaient un rumen contenant un nombre extraordinaire de bactéries, soit de 61 à 64 milliards par g.

Les auteurs concluent que l'emploi des antibiotiques ne peut être recommandé pour les ovins.

I,OOSLI (I95I) exprime la même opinion : " Dans l'état actuel des connaissances, il semble indésirable d'ajouter des antibiotiques à la nourriture des moutons".

Cependant, en ce qui concerne les agneaux seulement, on est en droit de penser que cette affirmation est trop catégorique et que l'action nuisible des antibiotiques qui a été observée par ColBY, RAU et al. provient del'emploi de trop fortes doses, ou d'une durée insuffisante des expériences.

Ainsi, répétant les expériences de Col,By, Wasserman et CunningHAM (I95I) observent que les agneaux recevant Ioo mg d'Auréomycine refusent tout ou partie de leur nourriture pendant 2 ou 3 jours, mais reviennent graduellement à une consommation normale, même si on continue la distribution d'antibiotiques. Au bout de I9 jours, les agneaux traités consommaient autant que les témoins et ils ne présentaient avec ceux-ci aucune différence de poids en moyenne. Une autre expérience de I9 jours, répétant la première, a donné les mêmes résultats. Dans les expériences précitées, les doses d'Auréomycine variaient de 40 à Ioo mg par jour.

Bien plus, JORDAN et BELL (I95I) utilisant les doses de 5 et $15 \mathrm{mg}$ d'Auréomycine par jour, avec 24 jeunes agneaux allaités, obtiennent, sur une moyenne de 6 semaines, des augmentations de gains moyens journaliers de poids vif de 18,5 et 7,4 p. Ioo, la dose la plus forte donnant le plus faible résultat. Tous les agneaux traités étaient normaux à tous points de vue. Avec 37 agneaux à l'engrais recevant les doses de 6 et ro, 8 mg d'Auréomycine par jour avec une ration de base constituée de maïs et de luzerne, ils obtiennent:

- des augmentations de gains moyens de 25,6 et II,I p. Ioo, la dose la plus forte donnant là encore le résultat le plus faible,

- des diminutions de l'indice de consommation de 22 et 20 p. Ioo.

Ces expériences sembleraient indiquer que la dose optima pour les jeunes agneaux allaités est voisine de $5 \mathrm{mg}$ d'Auréomycine par jour.

Dans 4 expériences ultérieures comprenant 200 agneaux, réalisées pour étudier l'action de 1'Auréomycine sur 1'engraissement des agneaux, JORDAN (I952) aboutit à des résultats semblables, qui le conduisirent aux conclusions suivantes :

$I^{0}$ On peut distribuer de 1'Auréomycine à des agneaux pendant roo jours, à des doses variant de 7 à $\mathrm{I} 4 \mathrm{mg}$ sans risquer de causer une perte d'appétit ou d'augmenter la fréquence des diarrhées.

$2^{\circ}$ Dans les essais entrepris, 1'Auréomycine n'a pas stimulé la consommation d'aliments avec la méme intensité qu'elle le fait chez les porcs. 
$3^{\circ} \mathrm{La}$ distribution d'Auréomycine au taux de $\mathrm{I} 4,4 \mathrm{mg}$ par jour a réduit la vitesse de croissance et a accru l'indice de consommation, dans les deux expériences où ce taux fut utilisé.

$4^{\circ}$ Utilisée aux doses de 7, 2 - Io,8 et I4,4 mg par jour, 1'Auréomycine n'a pu protéger complètement les agneaux de l'enterotoxémie ; cependant, celle-ci fut réduite considérablement.

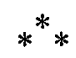

Il semble donc que si les ovins adultes réagissent défavorablement - comme les bovins adultes - à l'ingestion d'antibiotiques, les réponses des agneaux sont beancoup plus variables que celles des veaux.

\section{VII. - ETUDE DES ANTIBIOTIQUES CHEZ LES VOLAILLES}

Nous ne nous étendrons pas sur les différentes expériences qui ont mis en lumière le rôle des antibiotiques chez les poulets et dindons. Nous citerons seulement, dans la plupart des cas, les résultats obtenus : poulets.

$I^{0}$ Les antibiotiques augmentent la croissance des poussins et de io à I5\% (Cravens I950, Savage I95 I, Heuser I95I), de Io à $20 \%$ (BECHTEL I95I).

\section{et des dindonneaux.}

de I5 à $25 \%$ (SAVAge I95I), (Heuser I95I), ou de $20 \%$ (Cravens I950).

StoKstad, JUkEs et al. (I949 a), dans des expériences exposées précédemment (titre $I$, paragraphe $c$ ), ont obtenu avec des poulets une augmentation de $\mathrm{I} 8$ à 28 p. roo.

Cette augmentation est surtout sensible au cours du jeune âge, dans les 8 à I2 premières semaines (MC Ginnis I95). Elle est maxima pendant les 2 à 4 premières semaines (HEUSER I95I). Elle est nulle pour les animaux adultes ou les jeunes en fin de croissance (MC Ginnis I950).

D'après ScotT (I950 b), on peut expliquer pourquoi l'action des antibiotiques sur la croissance des dindons est en général supérieure à celle obtenue chez les poulets. Les travaux de Scott, HEUSER et Norris (r948) et de ScotT (I950 a) ont prouvé qu'il existait une vitamine non 
identifiée, indispensable à la croissance des dindonneaux, présente dans la caséine, le lait écrémé, les levures de brasserie, les solubles de distillerie et le jus de graminées. Fn l'absence de l'une de ces substances dans la ration, l'action des antibiotiques sur la croissance peut être très importante et dépasser celle observée chez les poulets. Mais quand la ration contient un antibiotique et cette vitamine non identifiée, l'augmentation de la croissance est d'environ Io p. Ioo pour des animaux âgés de 4 semaines, c'est-à-dire du mêne ordre de grandeur que celle généralement observée chez le poulet.

Il semble done que les antibiotiques peuvent couvrir ou épargner le besoin de l'animal en cette vitamine ; ainsi, leur action est d'autant plus nette que cette vitamine est plus rare dans la ration.

\section{$2^{\circ}$ Consommation et indice de consommation.}

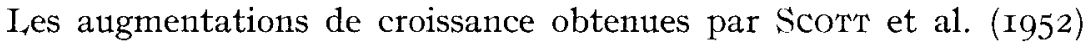
avec de 1'Auréomycine distribuée à des poulets, semblent dues à une augmentation des ingestions, mais le mécanisme de l'accroissement des Ingesta demeure inconnu. Cependant, les antibiotiques n'augmentent pas la croissance uniquement en augmentant le volume des ingesta; il y a aussi augmentation du rendement ou de l'efficacité alimentaire.

Ainsi, utilisant des dindonneaux répartis en 2 lots, un lot témoin et un lot recevant de la Pénicilline, Mc NeILL et al. (I952) maintiennent les ingesta des deux lots à la même valeur. Le poids à 4 semaines pour le lot expérimental a été nettement accru malgré cette restriction : 536 contre $472 \mathrm{~g}$ pour le lot témoin.

D'après SAVAGe (I95I), les antibiotiques diminuent l'indice de consommation de Io à $\mathrm{I} 5 \mathrm{p}$. Ioo chez les poulets.

$3^{\circ}$ Les antibiotiques n'ont aucune action sur les poulettes pondeuses ou reproductrices, pour la production des œufs ou le pouvoir d'éclosion, ni sur la qualité des poulets, contrairement à la vitamine BI2(STOKSTAD I950, BECHTEL, I95I).

D'après Heuser (I95I), les différences analytiques des carcasses sont faibles; il semble y avoir une tendance à une légère augmentation de la matière sèche. De plus, le pourcentage de matières grasses, ainsi que le poids total des graisses et des matières azotées, sont légèrement supérieurs chez les volailles ayant reçu des antibiotiques.

CARVEr (I95I) a montré chez les poulettes, que ro mg d'antibiotique par $\mathrm{kg}$ de ration n'ont aucune action sur le poids des œufs, leur production ou le pouvoir d'éclosion. 
BERG (I95I c) a obtenu les mêmes résultats négatifs avec 4,8 et I $2 \mathrm{mg}$ de 'Terramycine par $\mathrm{kg}$ de ration. La mortalité des poules pondeuses n'a pas décru non plus.

$4^{\text {o }}$ Ils améliorent le plumage, la pigmentation et l'aspect général des poussins (STOKSTAD I950).

\section{$5^{\circ}$ Action sur le plumage des dindonneaux.}

On sait que la lysine est indispensable à la prévention de la barre blanche des rémiges. Il semble, d'après les expériences de SLINGER (I95I), que l'APF et les antibiotiques augmentent le taux de lysine (et peut-être les taux de certains autres acides aminés) requis par les dindonneaux pour prévenir le plumage blanc. D'après l'auteur, il se pourrait que ces substances stimulent dans l'intestin la synthèse d'un ou plusieurs facteurs de croissance inconnus ou facilitent le métabolisme des éléments nutritifs ingérés.

\section{$6^{\circ}$ Besoins en vitamine B12 des poulets.}

REynol,DS, I,UTHER et al. (I95I) ont montré que la dose de Io $\mathrm{mg}$ de Terramycine par $\mathrm{kg}$ d'aliment abaisse les besoins de vitamine $\mathrm{BI} 2 \mathrm{du}$ poulet en croissance, de II à 6,6 \% par $\mathrm{kg}$ d'aliment, soit une diminution de $40 \mathrm{p}$. Ioo (et la réponse de croissance à la Terramycine est d'autant plus grande que la teneur de la ration en vitamine BI2 est plus basse). D’après Groschke (I950), ce besoin passe de I7 à II $\gamma$ par $\mathrm{kg}$ de régime avec des antibiotiques, Auréomycine ou Streptomycine.

Cette action d'épargne vis-à-vis de la vitamine BI2 se traduit par une augmentation du stockage de vitamine dans le foie, comme le montrent les expériences de Sunde et a1. (I95I), dont voici les résultats :

\section{I) Croissance}

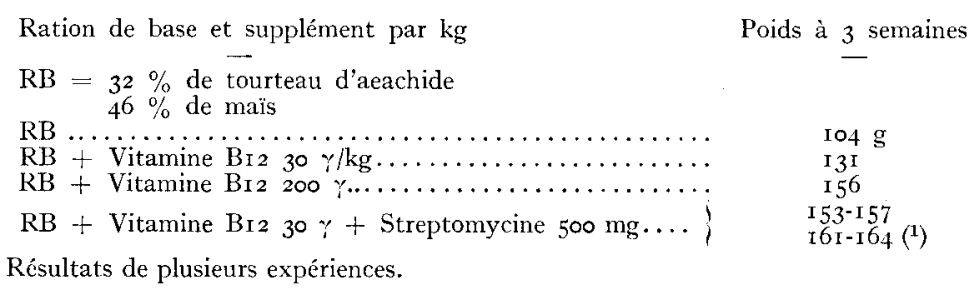

Ainsi, $30 \%$ de vitamine $\mathrm{BI} 2+500 \mathrm{mg}$ de Streptomycine par $\mathrm{kg}$ favorisent la croissance, approximativement de la même façon que $200 \%$ de vitamine $\mathrm{BI} 2$. 


\section{2) Stockage de vitamine B12 dans le foie}

\begin{tabular}{|c|c|c|c|}
\hline & Ration et supplément par $\mathrm{kg}$ & Poids à 4 sem. (g) & Vit. Br2 $\% / g$ de foie \\
\hline \multicolumn{4}{|c|}{$\begin{aligned} \mathrm{RB}= & 46 \% \text { de maïs } \\
& 22 \% \text { de tourteau de soja }\end{aligned}$} \\
\hline & Aucun...$\ldots \ldots \ldots \ldots \ldots \ldots$ & 283 & $0,02 \mathrm{I}$ \\
\hline $\mathrm{BB}+$ & Streptomycine $500 \mathrm{mg} . \ldots \ldots \ldots$ & 318 & 0,029 \\
\hline & Vitamine $B_{12} 7,5 \gamma \ldots \ldots \ldots \ldots \ldots \ldots \ldots \ldots \ldots$ & $32 \mathrm{I}$ & 0,100 \\
\hline $\mathrm{RR}+$ & Vitamine Br2 $7,5 \%+$ Streptomycine $500 \mathrm{mg} . .$. & 349 & 0,168 \\
\hline $\mathrm{RB}+$ & Vitamine Brz $30 \gamma_{1} \ldots \ldots \ldots \ldots \ldots \ldots \ldots \ldots \ldots$ & 325 & 0,239 \\
\hline $\mathrm{RB}+$ & Vitamine Bi2 $30 \%+$ Streptomycine $500 \mathrm{mg} \ldots$ & $3^{62}$ & 0,276 \\
\hline & 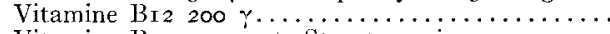 & 335 & 0,470 \\
\hline $\mathrm{RB}+$ & Vitamine BI2 $200 \gamma+$ Streptomycine $500 \mathrm{mg}$ & 354 & 0,825 \\
\hline
\end{tabular}

STOKSTAD et JukEs (I950 a) estiment également que 1'Auréomycine réduit les besoins en vitamine Br2 de 50 p. Ioo ; c'est ce qui explique en partie pourquoi les suppléments d'APF issus de la fermentation de 1'Auréomycine semblent contenir plus de vitamine BI2 quand on la dose par voie biologique avec des poulets que par analyse micrologique.

Signalons également les travaux de Oreson, Hutchings et WhiteHILI, (I950).

\section{$7^{\circ}$ Besoins en vitamine B12 des dindonneaux.}

Au contraire de ce qui a lieu chez les poulets, Arkinson et Couch (I95I) ont montré que la présence d'antibiotique, en augmentant la croissance, augmente le besoin en vitamine BI2; ainsi, le dindonneau en croissance n'a pas besoin de vitamine BI2 en 1'absence d'antibiotique. Par ailleurs, la présence dans le régime de Vitamine BI2 et de Streptomycine ou d'un APF d'Auréomycine, rend inutile la supplémentation en vitamines $\mathrm{du}$ groupe $\mathrm{B}$ (thiamine, riboflavine, acides nicotinique, pantothénique et folique, biotine, pyridoxine, choline). I, auteur suggère que les antibiotiques augmentent la synthèse des vitamines $B$ en agissant sur la microflore du tractus intestinal.

\section{So Besoins en protéines des poulets.}

I.a dose de 0,5 p. Ioo d'un sous-produit de fermentation de l'Auréomycine ou de $22 \mathrm{mg}$ d'Auréomycine cristallisée par $\mathrm{kg}$ de ration, réduirait les besoins en matières f́protéiques pour la croissance de 2 I à I9 p. Ioo, d'après MACHLIN et al. (I95I).

D'après SUNDE et al. (I95I), cette action d'épargne intéresserait spécialement la méthionine et la choline. Elle se produirait quand la méthionine est l'amino-acide limitant, mais n'aurait pas lieu si c'est la 1ysine. Ainsi, un mélange d'antibiotiques et de vitamine BI2 est impuissant à supprimer les effets de carence d'un régime à base de tourteau d'arachide, déficient en lysine. 
I. 'épargne des amino-acides et de la vitamine BI2 se ferait suivant le schéma suivant : la Streptomycine, d'après Moore et al. (1946), réduit considérablement le nombre des microbes coliformes du tractus intestinal du poulet. D'autre part, Davis et MiNGIOLI (I950) ont montré qu'Escherichia Coli avait une affinité marquée pour la méthionine et la vitamine BI2. Ainsi, la réduction du nombre des Escherichia Coli augmente la disponibilité en vitamine BI2 du poulet. Celle-ci, à son tour, favorise les processus de méthylation dans lesquels la choline et la méthionine sont impliquées.

Enfin, Thayeir (I950) signale des expériences effectuées au Washington State College : une ration pour poulets en croissance, à I6 p. Ioo de protéines et complémentée avec $22 \mathrm{mg}$ de Pénicilline par $\mathrm{kg}$ a permis d'obtenir la même croissance qu'une ration à $2 \mathrm{I}$ p. Ioo de Protéines, sans Pénicilline.

$9^{\circ}$ I1 semble que les antibiotiques puissent modifier la réponse des poulettes impubères aux astrogènes endogènes. Ainsi, Common et al. (I950) ont montré que l'addition dans le régime de $44 \mathrm{mg}$ d'Auréomycine $\mathrm{HCl}$ par kg de ration stimule l'augmentation des taux de calcium et de riboflavine du sérum, consécutive à une ingestion d'œstrogène.

IO ${ }^{\circ}$ Les besoins en antibiotiques des animaux en croissance ne peuvent être satisfaits par la litière accumulée (BECHTEL I95I).

II ${ }^{\circ}$ Les antibiotiques ne sont pas transmissibles des parents aux descendants. Ils ne s'accumulent pas dans les tissus et ne sont pas toxiques (BETCHTEL, I95I).

I $2^{\circ}$ La dose recommandée est de $5 \mathrm{mg} / \mathrm{kg}$.

Doses extrêmes : $2,2 \mathrm{mg}$ au moins à $22 \mathrm{mg}$ au plus par $\mathrm{kg}$ de ration. En pratique, pour les broilers, le taux est de 5 à $6 \mathrm{mg}$ d'antibiotique par kg (BECHTEL I95I). En fait, on a utilisé des doses inférieures (I,25 mg/kg) avec d'aussi bons résultats qu'en utilisant de plus grandes quantités, et des doses de beaucoup supérieures $(50 \mathrm{mg} / \mathrm{kg}$ ) sans observer d'effets nuisibles (HeUser I95I) — (cf. également 'Titre IV, paragraphe $f$ ).

I $3^{\circ}$ Pour les dindonneaux et d'après Mc Ginnis (I95I b), la Pénicilline, l'Auréomycine, la Streptomycine, la Terramycine, la Bacitracine, sont tous efficaces pour améliorer la croissance. Mais, à la suite de 3 expériences réalisées par Mc GrNNIs et al. (I95I) les auteurs concluent que c'est la Pénicilline qui est la plus efficace des quatre antibiotiques expérimentés (Bacitracine exclue).

D'après Branion et Hili, (I95I), la Chloromycetine n'améliore pas 
la çroissance, ni l'indice de consommation ; elle s'est même révélée légèrement toxique pour les dindonneaux, au taux de $25 \mathrm{mg} / \mathrm{kg}$.

Enfin, d'après MOORE et al. (1946), 1a Streptomycine est également toxique à la dose de ro ooo unités et plus pour roo g de nourriture (cf. titre II, paragraphe $a$ ).

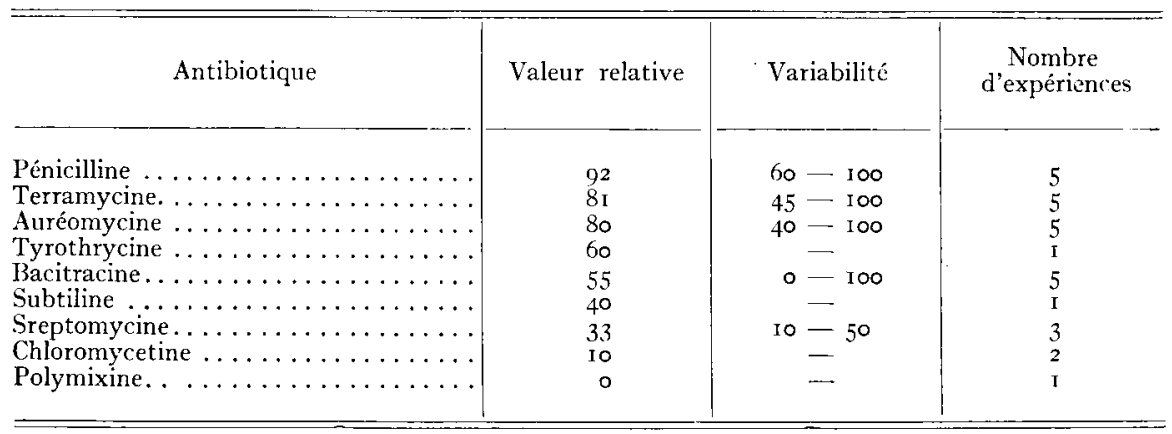

D'après Heuser (I95I), des essais systématiques ont été effectués à Cornell pour comparer l'action des antibiotiques sur des poulets âgés de 4 semaines. D'après le poids de ces poulets, on a classé les antibiotiques dans l'ordre du tableau précédent:

$14^{\circ}$ Des essais limités réalisés avec des faisans ont montré un plus grand accroissement de poids que les poulets, tandis que les canards présentèrent un gain de poids plus faible HEUSER (I95I).

\section{ETUDE DES ANTIBIOTIQUES SUR LES AUTRES ESPÈCES}

Rats. - D'après ST'ERN et MC Ginnis (I950) notamment, 1'Auréomycine, la Streptomycine et la Terramycine ont prouvé qu'ils étaient efficaces pour améliorer la croissance des jeunes rats et qu'ils agissaient également sur les rates allaitantes, d'une façon favorable. De plus, les jeunes rats sevrés dont les mères ont ingéré des antibiotiques ont une croissance plus rapide que les autres. Peut-être les quantités d'antibiotiques qui peuvent passer dans le lait maternel expliquent-elles ce fait.

Signalons également les travaux de JukEs et STockstad (I950 $b$ ) sur l'action de l'Auréomycine chez de jeunes rats déficients en Vitamine BI2 et son influence sur leur survie. Ceux de BratzLER et al. (I95I) sur 1'action de 1'Auréomycine, de la Streptomycine et de la Vitamine Biz dans la croissance; de Hwa LiH et Baumann (I95I), de Sauberlich (I952), sur les relations entre les antibiotiques et les besoins en vitamines de IIINKSWILleir, Baumann et al. (I95I) sur l'action de l'Auréomycine avec différentes formes de vitamine B6 dans la ration. 
Humains. - D'après STFRn et MC Ginnis (I950), il est possible qu'il soit désirable d'étendre le bénéfice des antibiotiques aux enfants malingres, pour augmenter leur croissance.

D'après STOKSTAD et JUKES (1950), des recherches cliniques ont été entreprises pour étudier l'influence des antibiotiques sur les enfants mal nourris et trop petits.

\section{CONCLUSION}

Malgré le grand nombre de travaux consacrés aux problèmes que pose l'emploi des antibiotiques dans l'alimentation, il est bien difficile de prétendre à des conclusions simples et nettes.

I'action généralement favorable qu'ils exercent sur les organismes supérieurs permet d'expliquer des observations plus anciennes, concernant l'effet heureux de l'ingestion de fumier de vache, de litière de volailles ou même de terre végétale (CunHa I948-I949 a). D'autre part, l'épargne de vitamine $\mathrm{BI} 2$ qu'ils permettent, leur influence sur le métabolisme des vita mines B, leur action sur l'appétit, laissent bien entrevoir une intervention que l'on peut rapprocher de celles des facteurs du complexe B (CAuserex, I95I). Mais agissent-ils directement dans la nutrition, ou manifestent-ils ces qualités par l'intermédiaire des microorganismes du tube digestif ? Aucune prettve certaine ne peut être apportée à l'appui d'une de ces hypothèses, bien que la seconde semble bénéficier d'un ensemble non négligeable de présomptions sérieuses.

Dans ce domaine, et à la lumière des premiers résultats, des recherches doivent pouvoir nous permettre d'élucider certains points, notamment leur influence sur la nutrition de l'individu : appétit, efficacité de la ration, digestibilité chez les monogastriques, actions d'épargne, flore du tube digestif.

Il est vraisemblable que lorsque le mécanisme de leur action sera mieux connu, des règles d'utilisation pourront être dégagées beaucoup plus facilement qu'à partir de la multitude, parfois apparemment incohérente, de résultats expérimentaux dont nous disposons à l'heure actuelle. On sait bien que les antibiotiques sont plus actifs sur des animaux chétifs que sur de bien portants, avec des rations carencées qu'avec des rations complètes, avec des protéines d'origine exclusivement végétale qu'avec des protéines animales. Mais, dès que la question de leur emploi se pose en détail, le choix de l'antibiotique et des doses devient délicat et comporte toujours une part de hasard.

C'est cette indécision qu'il faut lire dans les prudentes réflexions de 1'A gricultural Research Council britannique (1952); ayant été consulté sur l'opportunité de l'achat aux U. S. A. d'antibiotiques destinés aux 
animaux domestiques de Grande-Bretagne, il a suscité de nombreuses recherches, dont les premières viennent d'être achevées.

Il semble bien que, dans nos pays européens, l'emploi beaucoup plus large qu'aux U. S. A. de protéines animales dans l'alimentation de nos animaux de ferme, rende moins sensible, sur des animaux normaux, les résultats de l'adjonction de ces APF, aussi uniformes dans leur appellation que variés dans leur composition. La question de leur intérêt devient alors un simple problème de prix de revient. Mais il ne faut pas se dissimuler que, en Furope, le prix relativement plus élevé de ces suppléments et la plus faible différence entre les prix des protéines animales et végétales, doivent inciter nos praticiens à la prudence.

Peut-être n'en est-il pas de même quand il s'agit d'animaux mal venus et chétifs qui, chez les volailles et peut-être surtout chez les porcs, constituent pour les élevages une sérieuse entrave à leur rentabilité. I a transformation d'un " culot " de portée en animal normal semble représenter infiniment plus que la valeur des antibiotiques dépensés pour obtenir ce résultat. $\mathrm{L}_{\text {a }}$ suppression des troubles plus ou moins discrets que les éleveurs observent lors du transfert de porcherie à porcherie, ou pendant les saisons humides telles que l'automne et le début du printemps, sont peut-être également des objectifs en vue desquels les antibiotiques pourraient rendre des services économiques intéressants.

Cet emploi des antibiotiques doit naturellement être soumis à certaines précautions élémentaires dictées par un souci plus large de la santé humaine et de la "rusticité " de notre cheptel. Mais il faut bien convenir que si danger il y a, l'emploi de plus en plus fréquent des antibiotiques en thérapeutiques humaine et vétérinaire n'est pas fait pour rendre efficace les mestres que l'on peut être amené à édicter sur le plan purement zootechnique.

Sur ces points d'ordre plus pratique, mais non moins intéressants, des recherches peuvent donc apporter aux praticiens une aide utile: les inconnues ne manquent pas et peuvent susciter de nombreux travaux originaux.

\section{BIBLIOGRAPHIE}

Abraham (E. P.), Chain (E.), Fletcher (C. M.), Florey (H. W.), Gardner (A. D.), Heatley (N. G.) et Jennings (M. A.). - Further observations on Penicillin. Lancet, 2, p. I77, I94I.

Agricultural Research COUNeil. - Antibiotics in pig food. Brit. Agric. Bul., 5, I9, p. 48-59, I952.

AlfFord (J. A.) et RusofF (L. I.). - Unpublished data. In Journal of Dairy Science, 34, 7, p. 655, I95I.

Anderson (G. W.), Cunningham (J. D.) et Slinger (S. J.). - Effect of protein level and penicillin on growth and intestinal flora of chickens. $J$. of Nutr., 47, 2, p. I75-I89, I952. 
Anonyme. - Calf scours reported greatly decreased by aureomycin use Feedstuffs, 23, 38, p. I8, I95I.

Aschkenasy (A.). - La vitamine BI2 et le facteur des protéines animales. Ann. de la Nutr. et de l'Aliment., 6, 2, p. I4I-I67, I950.

ASSOCIATION OF AGRICULTURAL, FEED CONTROL OFFICIALS. - Rapport de la " 40 th annual Convention " des 4-5 octobre I950. In Feedstuffs, 22, 40, p. I-6I, et Feedstuffs, 22, 4I, p. I.

Atkinson (R L.) et Couch (J. R.). - Vitamin BI2, an APF concentrate, Aureomycin, Streptomycin, Liver " $\mathrm{L}$ " and fish meal and fish solubles in the nutrition of the poult. J. of Nutr., 44, 2, p. 249-263, I95I.

Baker (G. N.), Brinegar (M. J.), Blunn (C. T.) et Clawson (A. J.). - The effect of several levels of aureomycin fed to swine under different systems of management. $J$. of An. Sci., 10, 4, p. I035, I95I.

BARTLEY (E. E.). Results of feeding dairy calves APF supplement containing aureomycin. Kansas Formula Feed Conference, Manhattan, I6 janvier, I95I.

Bartley (E. E.), Fountaine (F. C.) et Atkeson (F. W.). - The effects of an APF concentrate containing aureomycin on the growth and well-being of young dairy calves. $J$. of An. Sci. 9, 4, p. 646. I950.

Bartiey (E. E.), Wheatcroft (K. L.), Claydon (T. J.), Fountaine (F. C.) et PArrish. - Effect of feeding aureomycin to dairy calves. $J$. of $A n$. Sci., 10, 4, p. I036, I95I.

Bechtel (H. E.). - How far can you travel on antibiotics. Présenté à la Convention de l'International Baby Chick Assn. St. Louis, I95I.

Becker (D. E.), Terrili (S. W.), Ulirey (D. E.) et Meade (R. J.). - The growth response of the pig to a dietary source of various antibacterial agents and to intramuscular injections of procaine penicillin. $J$. of $A n$. Sci., 10, 4, p. 1036, I95I.

Befson (W. M.). - Recent develoments in swine nutrition. Proc. Ohio An. Nutr. Conf. : Ohio State Univ. Colombus, nov. I950.

BeEson (W. M.). - Présenté au $\mathrm{I}^{\mathrm{e}}$ Congrès de Nutrition Animale, Uty Farm, St. Paul, I7-I8 sept, I95I $a$.

BEESON (W. M.). - Antibiotics and other new factors for the nutrition of swine. Proc. Cormell Nutr. Conf., 7-I4, I95I $b$.

Beli (M. C.), Whitehair (C. K.) et Gallup (W. D.). - The effect of aureomycin on digestion in steers. J. of An. Sci. 9, 4, p. 647, I950.

Beir (M. C.), Whitehatr (C. K.) et Gallup (W. D.). - The effect of aureomycin on digestion in steers. Proceed. Soc. Exp. Biol. Med., 16, 2, 28486 , I95I.

BenNison (R. W.), CATron (D. V.) et Maddock (H. M.). - Effects of antibiotics and vitamin BI2 on the pantothenic acid of growing-fattening swine. J. of $A n$. Sci., 10, 4, p. I038, I95I.

BERG (L. R.). - Antibiotics in feeds for broilers. Washington State Coll. Nutr. Conf. Seattle, April 2-3, I95 $a$ et $b$.

Berg (L. R.). - I95I c. Cité par CARVER (J. S.).

BIRD (H. R.). - Antibiotics in feed. Présenté à la " 40 th annual Convention" de l'Association of American Feed Control Officials, Washington, 5 oct., I950.

Bird (H. R.), Groschke (A. C.) et Rubin (M.). - Effect of arsenic acid derivatives in stimulating growth of chicks fed certain diets. Fed. Proc. \%, p. 283, I948.

Bird (H. R.), Groschie (A. C.) et Rubin (M.). - Effect of arsonic acid derivatives in stimulating growth of chickens. J. of Nutr. $3^{\text {ry }} 2$, p. 2 I5, r949.

BOHSTEDT (G.). - Antibiotics and vitamin $\mathrm{BI}_{2}$ in livestock feeding. Univ. Wisconsin Coll. Agric. Circ. 392, I950.

Bohstedt (G.). - New development in dairy and livestock feeding. Présenté à la Convention of the Retail Feed Assn., I95I. 
Bopst (L. F.). - Caution urged in use of antibiotics. Présenté à la " 40 th annual Convention of the Assoc. of American Feed Control Officials" Washington, 5, oct. I950.

Bosshardt (D. K.), Crereszko (L. S.), Buffington (A. C.) et Arnow (L. E.). - Accelerated growth of albino mice fed diets containing extracts of pancreas or liver. Arch. Bioch. 7, p. I-7, I945.

Bowland (J. P.), BEACON (S. E.) et MCEilroy (L. W.). - Animal protein factor and antibiotics supplementation of small grain rations for swine. J. of. An. Sci. 9, 4, 649; 10, 3, p. 629-37, I95I.

Branion (H. D.) et Hili (D. C.). - Comparative effects of antibiotics on the growth of turkey poults. Poul. Sci. 30, 6, p. 793-797, I95I.

Bratzler (J. W.) et BLACK (A.). - The effect of vitamin BI2, Streptomycin and aureomycin on growth and metabolism of the rat. $j$. of $A n$. Sci., 10, 4 , p. I040, 195I.

BRAUDE (R.) et MiTcheil (K. G.). - Antibiotics and liver extract for suckling pigs. British J. of Nutr., 5, 3-4, p. virr, I95I a.

BRAUde (R.), Kon (S. K.) et Mitcheli (K. G.). - The value of antibiotics for fattening pigs. I. As supplements to normal fattening ration. British $J$. of Nutr., 5, 3-4, VIII, I95I $b$.

Brides (J. H.), Dyer (I. A.) et BurkharT (W. C.). - Effects of penicillin and streptomycin on the growth rate and bacterial count in the feces of swine. J. An. Sci., 10, 4, p. I040, I95I.

Bridges (J. H.), IVyer (I. A.) et BuRkhart (W. C.). - Effects of penicillin and streptomycin on the growth rate and bacterial count in the feces of pigs. J. An. Sci. 11, 3, p. 474-80, I952.

Briggs (G. M.). - Antibiotics in poultry rations. Présenté à la Convention de l'International Baby Chick Assoc. Minneapolis, I950 a.

Briggs (C. M.). - Germ-free animals studies at Notre-Dame. Feedstuffs, 22, 24, p. IO-II, I950 b.

BRIGgs (J. E.). - Recent advances in animal nutrition. Présenté à l'Indiana Veterinary medical Association, I95I.

BRIGgs (G. M.) et BEESON (W. M.). - The supplementary effect of B-Vitamins, APF concentrates, and Streptomycin on growth of weanling pigs. $J$. of An. Sci. 2, 4, p. 649, I950.

Briggs (J. E.) et BEESON (W. M.). - Further studies on the supplementary value of aureomycin, streptomycin and vitamin $\mathrm{Br} 2$ in a plant protein ration for growing-fattening pigs. J. of $\mathrm{An}$. Sci., 10, 4, 820-828, I95I.

BRIGGS (J. E.), EILROD (R.) et BEESON (W. M.). - The effect of type of ration on the penicillin requirement for growing-fattening pigs. J. An. Sci., 10, 4, p. I04I, I95I.

Brinegar (M. J.) et WARner (D. R.). - Antibiotic studies with swine in dry lot and on alfalfa pasture. $J . A n$. Sci., 10, 4, p. I04I, I95I.

Brown (J. H.) et LUTHER (H. G.). - Effect of antibiotics and other growth stimulating substances in the rations of growing and fattening hogs. J. of $A$ n. Sci., 9, 4, p. 650, I950.

Brown (P. B.), Becker (D. E.), CARD (L. E.) et TERrill. (S. W.). - The effect of aureomycin on the rate of gain and efficiency of feed utilization by growing-fattening swine. $J . A n$. Sci., 10, 4, p: 1042, I95I.

Burnside (J. E..), Cunha ('T. J.), Eddwards (H. M.), Meadows (G. B.), Lamar (G. A.), Pearson (A. M.) et Glasscock (R. J.). - Response of the pig to APF, Br2 and Br2 b. Proc. Soc. Exp. Biol. Med., 74, r, p. I73, I950.

Burnside (J. E.), Grummer (R. H.), Phillips (P. H.) et Bohstedt (G.). The effect of vitamin BI2 and aureomycin when fed with high, intermediate, and low protein levels to swine. J. An. Sci., 10, 4, p. I042, I95I.

Carpenter (L. E.). - The effect of APF concentrates and antibiotics on the growth of swine. Ann. Report of the Hormel Institute of the University of Minnesota I949-I950, p. I9-24, I949 a. 
Carpentrer (L. E.). - Effects of feeding 3-nitro-4-hydroxy Phenyl arsonic acid to swine. Annal Report of the Hormel Institute of the University of Minnesota I949-I950, p. 55-59, I949 $b$.

CARPENTER (L. E.). - The effect of products obtained from streptomyces aureofaciens fermentation on the growth and reproduuction of swine. Annual report of the Hormel Institute of the University of Minnesota I949-I950, p. 74-80, I949 c.

CARPENTER (L. E.). - Effect of aureomycin on the growth of weaned pigs. Arch. Biochem. 2\%, 2, p. 469-7I, x950 a.

CARPENTER (L. E.). - Effect of 3-nitro-4-hydroxy phenyl arsonic acid on the growth of swine. J. of $A n$. Sci., 9, 4, 65I, I950 b.

CARPenter ( $\mathrm{L}_{\text {. }} \mathrm{E}$.). - E Effect of an APF concentrate containing aureomycin on gestating and lactating swine. $J$. of $A n$. Sci., 9, 4, 65I, I950 $c$.

CARPEnter (L. E.). - Effect of an APF concentrate containing aureomycin on gestating, lactating and growing swine. J. of An. Sci., 10, 3, p. 657664 , I95I.

CARver (J. S.). - Antibiotics in feeds for laying hens. Présenté à la "Washington State College Nutrition Conference, "Seattle, April I95I.

CARy (C. A.), Hartman (A. M.), Dryden (L. P.) et Likely (G. D.) - - An unidentified factor essential for rat growth. Fed. Proc. 5, I Pt. 2, p. I28, I946.

Catron (D. V.). - Recent development in swine nutrition. Vet. Med. 44, 5, p. 2I5-220, I949.

Catron (D. V.) et Culbertson (C. C.). - Iowa Farm Sci. 3, p. 3, I949. Cité in Arch. Biochem. I949, 23, 2, p. 324.

Catron (D. V.). - Iowa State Coll. Unpublished data, cité in Feedstuffs, I950, 22, 26, p. I7, I950 a.

Catron (D. V.), Speer (V. C.), Maddock (H. M.) et Vohs (R. I.). - Effect of different levels of aureomycin with and without vitamin $\mathrm{BI} 2$ on growing fattening swine. J. of $A n$. Sci., 94 , p. 652, I950 $b$.

Catron (D. V.), Hoerlein (A. B.), BennetT (P. C.), CUFF (P. W.) et Homeyer (P. G.). - Effect of vitamin Br2, $\mathrm{APF}$ and antibiotics on enteritis in swine. J. of An. Sci. 9, 4, p. 65I, I950 c.

Catron (D. V.). - Cité par Yantis (H. E.) et Gates (C. L.). Feedstuffs, 23, 48 , p. 6-8, r95r.

Catron (D. V.), Jensen (A. H.), Maddock (H. M.). - Reevaluation of protein levels for growing-fattening pigs in drylot. $J$. of $A n$. Sci. I95I, 10, 4, p. I043; do I952, 11, 2 p. 22 I, I95I $a$.

Catron (D. V.), Lane (M. D.), Payne (L.) et Maddock (H. M.). - Effects of antibiotics on nutrient absorption in swine. $J$. An. Sci., 10, 4, I043, I95I $b$.

Catron (D.). - Antibiotics in swine nutrition. Proc. of the Forth Research Conf. Amer Meat Inst. p. I2-2 I, 1952.

Causeret (J.). - Carences vitaminiques et appétit. L'alimentation et la Vie, 30, I-2-3, p. 39, I95I.

Chain (E.), Florey (H. W.), Gardner (A. D.), Heatley (N. G.), Jemmings (M, A.), OrR-Ewing (J.) et Sanders (A.G.).-Lancet, 11, p. 226, r940.Cité in Exposés annuels de Biochimie médicale r946, 6 e Série; p. 225-286, et in Annual Reviere of Biochemistry, I948, XVII, p. 657-704.

Chain (E.). - The chemistry of penicillin. Annual Review of Biochemistry, $X V I I$, p. 657-704, I948.

Colby (R. W.), RAU (F. A.) et MrLier (J. C.). - The effect of various antibiotics on fattening lambs. $J$. of $A n$. Sci., 9, 4, p. 652, I950 a.

Corby (R. W.), RAU (F. A.) et Couch (J. R.). - Effect of feeding an "APF" concentrate to young lambs. Amer. J. Physiol., 163, 2, p. 4I8, I950 b. 
Common (R. H.), KeEFE (T. J.), Burgess (R.) et Maw (W. A.). - Modification of the biochemical responses of the immature pullet to cestrogen by means of dietary aureomycin. Nature, 166, 4232, p. 992, I950.

Colby (R. W.), RAU (F. A.) et DUnN (R. C.). - Effect of feeding aureomycin to fattening lambs. Proc. Soc. Exp. Biol. Med., 75, I, p. 234, I95I.

Covch (R. J.) et REED (R.). - Rapport présenté à la Gordon Research Conf. août I949.

Cravens (W. W.). - Vitamin BI2 and the antibiotics in animal nutrition. Feedstuffs, 22, 49, p. 54-56, I950.

Cuff (P. W.), Maddock (H. M.), Speer (V. C.) et Catron (D. V.). - Rations for slow-growing (runt) pigs. $J$. of $A n$. Sci., 9, 4, p. 653, I950.

Cuff (P. W. W.), Maddock (H. M.), Speer (V. C.) et Catron (D. V.). Effect of different antibiotics on growing fattening swine. Iowa State Coll. J. Sci., 25, 4, p. 575-80, I95I.

Cunha ('T. J.), Col By (R. W.), Hodgskiss (H. W.), Huang (T. C.) et EinsMINGER (M. E.). - Alfalfa and soil as a source of an unindentified factor and the value of other vitamins for the young pig. J. of An.Sci., $\boldsymbol{7}, 4$, p. 523, 1948 .

Cunha (T. J.), Burnside (J. E.), Buschman (D. M.), Glasscock (R. S.), Pearson (A. M.), Shealy (A. L.). - Effect of vitamin Bi2, APF and soil for pig growth. Arch. Bioch., 23, 2, p. 324, I949 a.

Cunha (T. J.), Burnside (J. E.), Hopper (H. H.), Pearson (A. M.) et GlasSCOCK (R. S.). - Effect of animal protein factor supplement, BI2 methionine and soil on corn rations supplemented with peanut, soybean and fish meals. J. of $A n$. Sci., 8, 4, p. 6I6-6I7, I949 b.

Cunha ('T. J.), Hopper (H. H.), Burnside (J. E.), Pearson (R. M.), GlasSCOCK (R. S.) et SHEAIY (A. L.). - Effect of vitamin BI2 and APF supplement on methionine needs of the pig. Arch. Bioch., 23, 3, p. 5IO, I949 $c$.

Cunna (T. J.). - Effect of aureopycin on the pig. Feedstuffs, 22, I7, p. 26, I950 $a$.

Cunha (T: J.). - Antibiotics effect may differ. Feedstuffs, 23 40, p. I2 r950 $b$.

Cunha (T. J.), Meadows (G. B.), Edwards (H. M.), Seweli (R. F.), Shawver (G. B.), Pearson (A. M.) et Glasscock (R. S.). - Effect of aureomycin and other antibiotics on the pig. $J$. of $A n$. Sci., 9, 4, p. 653, I950 a.

Cunha (T. J.), Edpwards (H. M.), Meadows (G. B.), Benson (R. H.), Pearson (A. M.) et Grasscock (R. S.). - APF, BI2, BI3, and related factors for the pig. J. of An. Sci., 9, 4, p. 653, I950 b.

Cunha (T. J.), Burnside (J. E.), Meadows (G. B.), Eddwards (H.M.),Benson (R. H.), Pearson (A. M.) et Glasscock (R. S.). - Eiffect of APF supplement on efficiency on feed utilisation for the pig. J. of An. Sci., 9, 4, p. 6I5-6I8, I950 c.

Cunha ('T. J.), Burnside (J. E.), Edwards (H. M.), Meadows (G. B.), Benson (R. H.), Pearson (A. M.) et Glasscock (R. S.). - Effect of animal protein factor on lowering protein needs of the pig. Arch. Bioch., 25, 2 , p. 455 , I950 $d$.

Cunha (T. J.), Meadows (G. B.), Fidwards (H. M.), Sewell. (R. F.), Pearson (A. M.) et Glasscock (R. S.). - A comparison of aureomycin, streptomycin, penicillin and an aureomycin BI2 feed supplement for pig. Arch. Bioch., 30 2, p. 269-27I, I95I.

Cuthbertson (W. F. J.) et Lester SMith (E.). - Chromatography of the vitamin BI2 groups of factors. Bioch. J. 44, I, Proc. V-VI, I949.

Davis (B. D.) et Mingioli (E. S.). - Mutants of Escherichia Coli requiring methionine or vitamin BI2. J. Bact., 60, p. I7-18, I950.

DAvis (R. L.) et BRIGGS (G. M.). - Studies with antibiotics in chick and poult starting rations. Poul. Sci., 30, 5, p. 767-77I, I95I. 
Dobbins (F.). - Antibiotic, BI2 and other requirements of swine. Présenté à la Mississipi Valley Veterinary Medical Assoc. I95I.

Dornbush (A. C.) et PeicaK (E. J.). - Ann. N. Y. Acad. of Sci. 51, p. 2 I8; 1948. Cité in Proc. Soc. for Exp. Biol. Med. I950, 73, 3, p. 523-528.

Dubos (R. J.). - Bacteriacal effect of an extract of a soil bacillus on germpositive cocci. Proc. Soc. Exp. Biol., 40, 3I I, I939.

Duggar (B. M.). - Ann. New York Acad. Sci. 51, p. I75-342, I948. Cité in Annual Review of Biochem. I949, 18, p. 559-594; et in J. Biol. Chem. I $949,180,2$, p. 647.

Dyer (I. A.), TerriLI. (S. W.) et Krider (J. L.). - The effect of adding APF supplements and concentrates containing supplementary growth factors to a corn-soybean oil meal ration for weanling pigs. J. of $A n$. Sci. 93 , p. $28 \mathrm{I}-288,1950$.

Edwards (H. M.), Cunha (T. J.), Mealows (G. B.), Sewel. (R. F.) et Shawver (C. G.). - Observations on aureomycin and APF for the pig. Proc. Soc. Exp. Biol. Med., 75, 2, p. 445, I950.

Emerson (G. A.), Wurtz (E.) et ZaNeTti (M. E.). - Vitamin Biz a growth factor for young rats. Feder. Proc. 8, p. 38I-382, I949.

Ferguson (J. R.). - M. S. Thesis Cornell Univ. Ithaca, New York. Cité in Proc. 1951. Cornell Nutr. Cont. p. 37, I95I.

FÉvrier (R.). - L'indice de consommation est-il chez le pore le témoin fidèle de l'efficacité d'une ration ? Ann. de Zoot., 1, I, p. I75-I84, I952.

FERrando (R.). - Journées du Porc, Lyon, à paraître, I952.

Finlay (A. C.), Hobby (C. L.), Pan (S. Y.), Regna (P. P.), Routien (J. B.), SeEly (D. B.), Shuli (G. M.), Sobin (B. A.), Solomons (I. A.), Vinson (J. W.) et Kane (J. H.). - Science, 111, p. 85, I950. Cité in Annual Review of Bioch. I95I, 20, p. 367-4I4.

FlemiNG (A.). - L'action antibactérielle des cultures de pénicillium avec référence spéciale concernant leur emploi dans l'isolement de B. influenzae British J. Expt. Path. 10, p. 226, I929. D'après Sanní̂́ (C.), I 946.

JORDAN (R. M.). - Aureomycin supplements in lambs fattening rations. J. An. Sci., 11, 3, p. 566-72, I952.

Fried (J.) et Wintersteiner (O.). - Science, 101, p. 6I3-6I5, - I945. Cité in Annual Review" of Biochemistry I949, 18, p. 559-594.

Gilis (M. B.) et Norris (L. C.). - Effect of the animal protein factor on the requirement for methylating compounds. J. of Biol. Chem. 179, p. 487488 , I949.

GroschKe (A. C.). - Relations of growth stimulating properties of antibiotics to unidentified growth factors required by the chick. Poul. Sci., 29, 5 , p. 760, I950.

Groschke (A. C.) et Evans (R. J.). - Effect of antibiotics, synthetic vitamins vitamin BI2 and an APF supplement on chick growth. Poul. Sci. 29, 4, p. 6I6-6I8, I $95^{\circ}$.

Grummer. - Cité par Robison, I95I:

Hammond (J. C.). - Dried cow manure and dried rumen contents as a partial substitute for alfalfa leaf meal. Poul Sci. 23, 6, p. 47I-76, I944.

Hanson (L. E.). Ferrin (E. F.), Anderson (P. A.) et Aunan (W. J.). - Do pigs over I25 L,b. benefit from antibiotics. Feedstuffs, 23, 42, p. 42-46, I95I $a$.

Hanson (L. E.), Ferrin (E. F.) et Aunan (W. J.). - Antibiotics for pigs on pasture Feedstuffs, 23, 47, p. 22-23, I95 I $b$.

Hartman (A. M.), Dryden (I. P.) et Cary (C. A.). - Deficiencies other than vitamin A in vitamin A free diets. J. of Biol. Chem. 140, IV-LV, I94I.

Hartman (A. M.), Dryden (L. P.) et Cary (C. A.). - A role of vitamin BI2 in the normal mammal. Arch. Bioch. 23, p. I65-I68, I949.

Heidebrecht (A. A.). - New factors in swine feeding. Proc. of the Oklahoma Formula Feed Conf. p. I9, I950. 
Heidebrecht (A. A.), Ross (O. B.), McVicar (R. W.) et Whitehair (C. K.). - Reproduction and lactation performance of sows fed vitamin and A. P. F. concentrates. $J$. of $A n$. Sci. 9, 4, p. 658, I950 a.

Heidebrechir (A. A.), Ross (O. B.), Whitehair (C. K.) et McVicar (R. W.). - The effect of various levels of penicillin upon growth of pigs. Oklahoma Agric. Exp. Sta. Miscell. Publ. MP 22, p. 72-75, I950 b.

Heidebrecht (A. A.), Ross (O. B.), Whitehair (C. K.), McVicar (R. W.) et SMITH (W. M.). - Reproduction and lactation performance of sows fed B vitamins and aureomycin. Oklahoma Agric. Exp. Sta. Misc. Publ. MP 22, p. 75-77, r950 c.

Heidebrecht (A. A.), Ross (O. B.), Whitehair (C. K.) et McVicar (R. W.). - The value of adding aureomycin to a good ration for growing pigs. Oklahoma Agric. Exp. Sta. Misc. Publ. MP 22, p. 79-8I, I950 d.

Heidebrecht (A. A.), Ross (O. B.), Whitehair (C. K.), McVicar (R. W.) et SMITH (W. M.). - The effect of antibiotics, combinations of antibiotics and vitamin $\mathrm{B}_{\mathrm{I} 2}$ and sulfathalidine on unthrifty pigs. Oklahoma Agric. Exp. Sta. Misc. Publ. MP 22, p. 77-79, 1950 e.

Heuser (G. F.). - Studies on antibiotics for poultry. Proc. 1951. Cornell Nutr. Conf., p. 25-26, I95I.

Hibbs (J. W.) et Pounden (W. D.). - The performance of rumen inoculated calves fed a high roughage ration with and without A. P. F. supplement. J. of An. Sci. 9, 4, p. 659, I950.

HOEFER (J. A.), LUECKE (R. W.) et THORP (F.). - The effect of terramycin on the growth of pigs fed different levels of protein. J. An.Sci. 10, 4, p. I049, et 11, 3, p. 455-459, I95I.

Hogan (P. R.). - Les antibiotiques dans 1'alimentation animale. Bul. de l'Univ. de Columbia, Missouri, Coll. d'Agric., I2 sept., I95o.

Hogan (A. C.) et Anderson (G. C.). - Vitamin Biz in swine nutrition. Feder. Proc., 8, p. 385-386, I949.

Huhtanen (C. N.), Saunders (R. K.), Gali. (L. S.). - Some differences in adult and infant rumen flora of cattle on practical ration. $J$. of $A n$. Sci., 10, 4, p. I049-I050, I95I.

Jacobson (N. L.), KafFetzakis (J. G.) et MuRLEy (W. R.). - Response of ruminating dairy calves to aureomycin feeding. J. An.Sci. 10, 4, p. 1050, I95I.

JAFFÉ (W. G.) et ELLEHJEM (C. A.). - Fractionation of growth-stimulating factor in liver. J. Biol. Chem. 169, p. 287-293, I947.

Johnson (B. C.). - Am. Chem. Soc. Abst. Avril, I5 a, I95o. Cité in Proc. Soc. Exp. Biol. Med. 1950, 75, 3, p. 7I0-7II.

Jordan (R. M.) et BELL (T. D.). - Effect of aureomycin on growth and fattening lambs. $J$. of $A$ n. Sci. 10, 4, p. I05I, I95r.

JUkEs (T. H.). - Some effects of aureomycin and other antibacterial substances on the growth of chickens, pigs, turkeys. Feedstuffs, 22, 25 , p. $46-48$, I950.

Jukes (T. H.). - - Présenté à la Kansas Feed Conf., I6-I7 janv. I95 I $a$.

Jukes (T. H.). - Présenté à la Texas Nutr. Conf. 25-26 oct. I95I $b$.

Jukes (T. H.), Stokstad (E. L. R.), Taylor (R. R.), Cunha (T. J.), Édwards (H. M.) et MEADOws (G. B.). - Growth promoting effect of aureomycin on pigs. Arch. Bioch., 26, 2, p. 324, I950 a.

JUKES (T. H.) et StoksTAD (E. L. R.). - Growth promoting effects of aureomycin and other supplements. $J$. of An. Sci., 9, 4, p. 660, I950 b.

Kunkel (H. O.), Simpson (R. E.), Pearson (P. B.), Ol,cese (O.) et SchweiGERT (B. S.). - Effect of liver extract on growth of rabbits. Proc. Soc. Exp. Biol. Med. 68, p. I22-124, I948.

Lasley (J. F.), Anderson (G. C.) et Hogan (A. G.). - A. P. F. supplements in rations for growing pigs. J. of $A n$. Sci., 9, 4, p. 662, I950 a. 
LASley (J. F.). - Présenté à la Second Ann. Miss. Formula Feed Conf. Univ. of Miss., 8-9 nov. I950.

LEpley (K. C.), Catron (D. W.) et Culbertson (C. C.). - Comparaison of different sources of animal protein factor for growing fattening pigs. J. of An. Sci., 8, 4, p. 625, I949.

Lepley (K. C.), Catron (D. V.) et Culbertson (C. C.). - Dried whole aureomycin mash and meat and bone scraps for growing fattening swine. $J$. of $A n$. Sci. 9, 4, p. 608-6r4, I950.

LEROY (A. M.) et LERY (G.). - Expériences sur la croissance des porcs pendant la période d'allaitement et de sevrage. Ann. Agronomiques, I er trimestre, I946.

LiH (H.), BaumanN (C. A.). - Effects of certain antibiotics on the growth of rat fed diets limiting in thiamine, riboflavin or pantothenic acid. $J$. of Nutr. 45, I, p. I43-I52, I95I.

Lilite (R. J.) et BIRD (H. R.). - Présenté à 1'Inform. Poul. Nutr. Conf. Atlantic City, April I950.

Lilifie (R. J.), Denton (C. A.) et BiRd (H. B.). - Relation of vitamin Bi2 to the growth factor present in cow manure. J. Biol. Chem. 176, p. I477, I 948 .

LiNKSWILLER (H.), BAumanN (C. A.) et Sweli (E. E.). - E Effect of aureomycin on the response of rats to various forms of vitamin B6. J. of Nutr. 43, 4, p. 565-73, I95I.

LoosLI (J. K.). - The amino-acid requirement of swine. Proc. of the 1950, Cornell Nutr. Conf., r950.

Loosli (J. K.). - Studies of antibiotics for ruminants. Proc. of the 1951 Cornell Nutr. Conf., p. 33-37, I95I.

Loosli (J. K.) et WALIACE (H. D.). - Influence of APF and aureomycin on the growth of dairy calves. Proc. Soc. Exp. Biol. Med., 75, 2, p. 53I, I950 $a$.

Loosli (J. K.), Wasserman (R. H.) et Gall (L. S.). - Antibiotics studies with dairy calves. $J$. of Dairy Sci., 34, 6, p. 50, I950 $b$.

LUECKE (R. W.). - The effect of vitamin Br2, APF and antibiotics on the growth of the weanling pig. Proc. of the 1950 Cornell Nutr. Conf., p. 35, I950.

Luecke (R. W.), McMillen (W. N.) et ThORP (F-Junior). - The effect of vitamin BI2 animal protein factor and streptomycin on the growth of young pigs. Arch Bioch. 26, 2, p. 326, I950 a.

Luecke (R. W.), Newland (H. W.), McMilien (W. M.) et Thorp (F. Junior). - The effect of antibiotics fed at low levels on the growth of weanling pigs. J. of. An. Sci., 9, 4, p. 662, I950 $b$.

Luecke (R. W.), Thorp (F. Junior), NeWLAND (H. W.) et McMillen (W. N.). The growth promoting effects of various antibiotics on pigs. $J$. of $A n$. Sci., 10, 2, p. 538-542, I95I.

LUTHER (H. G.). - Development of synthetic sow's milk announced by Pfizer and Co-Cité in Feedstuffs I95 $, 23,47$, p. I-65, I95 $\mathrm{x}$ a.

Luther (H. G.). - Development of synthetic sow's milk described. Cité in Feedstuffs I95I, 23, 48, p. IO-I4, I95I $b$.

LUTHER (H. G.) et BROWN (J. H.). - Antibiotics in ration of hogs-effect of withdrawal and long term feeding, levels and comparison of antibiotics including anti-fungal type. $J$. An. Sci., 10, 4, ro55, I95I $a$.

I.UTHER (H. G.) et Brown (J. H.). - Sows milk substitute for practical feeding of baby pigs. Effects of various levels of antibiotics, fat, solid, protein, etc. $J$. of $A n$. Sci., 10, 4, p. I055, I95 I $b$.

Machebceuf (M.). - Non publié. Cours Faculté des Sci., I95I-I952, I952.

MAchlin (L. J.), Denton (C. A.), KeilogG (W. L.) et Bird (H. R.). - Effect of dietary antibiotic upon feed efficiency and protein requirements of growing chickens. Poul. Sci., 31, I, p. 106-108, I952. 
Machlin (L. J.), Denton (C. A.), Keliog (W. L.) et Bird (H. R.). - Antibiotics may reduce protein needs of chicks. Cité par U.S. Dept. of A gric. Scient. Conf. des "Federated Soc. of Exp. Biology ", 29 avril I95I.

McGinnis (J.). - Antibiotics as growth stimulants for chicks and turkey poults. Proc. of the 1950 Cornell. Nutr. Conf., p. 40-46, I950.

McGinnis (J.). - I95I a. Cité par Plonsky (J. C.).

McGinnis (J. R.). - Unidentified growth factors for chicks and poults. Présenté à la Washington State Coll. Nutr. Conf., 2-3 avril, I95I b.

McGinnis (J. R.), Stephenson (E. L.), Levadie (B. T. H.), Carver (J. S.), Gartbai,ni (J. A.), Ijichi (K.), SNeli (N. S.) et Lewis (J. C.). - Response of chicks and turkeys poults to vitamine BI2 supplements produced by fermentation with different organisms. Abst. of Paper 116th. Meet. Amer. Chem. Soc., 42 A, I949.

McGinnis (J.), Stern (J. R.), Wilcox (R. A.) et Carver (J. S.). - The effect of different antibiotics on growth of turkey poults. Poul. Sci., 30, 4, p. 492-96, I95I.

MCGinnis (J.), Berg (R. L.), StERN (J. R.), Wilcox (R. A.) et Bearse (G. E.). - The effect of aureomycin and streptomycin on growth of chicks and turkey poults. Poul. Sci., 29, 5, p. 77I, I950.

Mcintire (J. B.), Henderson (I. M.), Schweigert (B. S.) et Elivehjem (C. A.) - Growth of rats on synthetic diets containing limiting amounts of thiamine. Proc. Soc. Exp. Biol. Med., 54, p. 98-Ioo, I943.

MCMEEKAN (G. P.). - Growth and development of the pig with special reference to carcass quality characteristics. Part. II. Effect of the plane of nutrition on form and composition of the bacon pig. J. of Agric. Sci., 30, p. 5II, I940.

MCNeill-SiebURTh, (J.) Stern (J. R.) et McGinnis (J.). - The effect of antibiotics and fecal preparation on the growth of turkey poults. Poul. Sci., 31, 4, p. $625-27,1952$.

MaSieburth (J. M.), Gutierrez (J.), McGinnis (J.), Stern (J. R.) et SchneiDER (B. H.). - Effect of antibiotics on intestinal microflora and on growth of turkeys and pigs. Proc. Soc. Exp. Biol. Med., 76, I, p. I5, I95I.

MCVICAR (R. W.). - The significance of the new factors for the feed industry. Proc. of the Oklahoma Feed Cont., p. I9-2I, I950.

Mapson (L. W.). - Evidence of the existence of a dietary principale stimulating general growth and lactation. Biochem. J. 26, p. 970-986, I932.

MAPSON (I. W.). - A deficiency disorder induced in suckling young rats bred on a purified synthetic diet with "Glaxocasein " (caseinogen) as sole source of protein. Bioch. J. 27, p. I06I-I068, 1933.

MARCH (B.) et BIELY (J.). - The effect of feeding aureomycin on the bacterial count of chick feces. Poul. Sci., 31, I, p. I77-I78, I952.

MILIER (R. C.), Gobbite (J. L.) et Kunns (K. J.). - Response of pigs to feeding of vitamin BI2, streptomycin and sulfathalidine. Proc. Soc. Exp. Biol. Med., 78, I, p. I6I-9, I95I.

Minot (G. R.) et Murphy. - J. Amer. Med. Assoc., 87, p. 470 ; Cité in Ann. de la Nutr. et Aliment., I950, IV, 2, p. I4I-I67, I926.

MollgaARD (H.). - Fundamental issues of modern physiology concerning the vitamin $\mathrm{B}$ complex. VI $\mathrm{e}$ Congr. Intern. de Zoot., II, p. 7-60, I952.

Moore (P. R.), Everson (H.), LuCKey (T. D.), MCCoy, EivehJEM (C. A.) et HART (E. B.). - Use of sulfasuxidine, streptothricin and streptomycin in nutritional studies with the chick. J. biol. Chem., 165, p. 437-44I, I946.

MoRehouse (N. F.). - Accelerated growth in chickens and turkeys produced by 3-nitro-4-hydroxyphenyl arsonic acid. Poul. Sci., 28, 3, p. 375, I949.

Morehouse (N. F. et MAYFIELD (O. J.). - The effect of some aryl arsonic acids on experimental coccidiosis infection in chickens. J. Parasitol., 32, p. $20,1946$. 
MORRISON (S. H.) et DeAL (J. F.). - Effect of APF (antibiotic feed supplement) supplementation during the first two weeks of life on the wellbeing and growth of dairy heifers. J. An. Sci., 10, 4, p. I057, I95I.

Murdock (F. R.). - Présenté à la Washington State Coll. Nutr. Conf. Seattle 2-3 avril I95I.

Murley (W. R.), Jacobson (N. I.), Wing (J. M.) et Stoddard (G. E.). - The response to aureomycin supplementation of young dairy calves fed various "practical " and restricted diets. J. of Dairy Sci., 34, 6, p. 500, I95I $a$.

Murley (W. R.), Alien (R. S.) et Jacobson (N. L.). - - The effect of aureomycin on feed nutrient utilization by young dairy calves. $J$. An. Sci., 10, 4, p. I057, I95I $b$.

Nesheim (R. O.) et Johnson (B. C.). - Response of pigs to streptomycin. Proc. Soc. Exp. Biol. Med., 75, 3, p. 709, I950.

Nesheim (R. O.), KRider (J. L.) et Johnson (B. C.). - Antibiotics, whey and APF for baby pigs. J. of $A n$. Sci., 9, 4, p. 664, I950 $b$.

Nestler (R. B.), BYerly (T. C.) Elitis (N. R.) et Titus (H. W.). - A new factor, not vitamin GI, necessary for hatchability. Poul. Sci., 15, p. 67$70,1936$.

Neumann (A. L.), James (M. F.), Krider (J. L.) et Johnson (B. C.). - Essentiality of vitamin $\mathrm{BI} 2$ for the baby pig with preliminary quantitative data. Feder. Proc. 8, p. 39I, I949.

Neumann (A. L.), Snapp (R. R.) et Gali (L. S.). - The long time effect of feeding aureomycin to fattening beef cattle, with bacteriological data. J. An.Sci., 10, 4, 0. I058, I95I.

Nicholl (C. A.), Robblee (A. R.), Cravens (W. W.) et Eilvehjem (C. A.). Activity of vitamin BI2 in the growth of chicks. J. of Biol. Chem. 1\%, p. 4I9-420, 1947 .

Noland (P. R.), Stephenson (E. L.), Neison (T. S.) et Tucker (D. L.). Response of baby pigs to antibiotics. J. An. Sci., 10, 4, p. I059, I95I.

Nutr. Review's. - Activity of microbial animal factor concentrates in pernicious anemia, 7 , I, p. IO-II, I949.

Nutr. Reviews. - Growth promoting effects of antibiotics in animals, 8, ro, p. 298-300, I950.

Oleson (J. J.), Hutchings (B. L.) et Whitehili (R.). - The effect of feeding aureomycin on the Vitamin Br2 requirements of the chick. Arch. Biochem., 29, p. 334-338, I950.

Olsson (N.) et Olofsson (N. E.). - Forsok med. APF Preparat. vid uppfodning av ung och-gödsvin. Svenska. Svinavelsfor. Tidskr. 5, p. 7487 , I95I $a$.

Orsson (N.) et Olofsson (N. E.). - Forsok med APF preparat. resp. Aureomycin vid uppfödning av ung-och-gödsvin. II. Svenska Svinave. Tidskr. 9, p. I37-I54, I95I $b$.

OTT (W. H.), Rickes (E. L.), WoOD (T. R.). - Activity of crystalline vitamin BI2 for chick growth. J. Biol. Chem., 174, p. I047-I048, I948.

Pasteur (L.), Joubert. - C. R. Acad. Sci. Paris, 85, p. Ior, 1877. Cité in Exposé annuels de Biochimie medic. I946, 6e série, p. 225-280.

Peck (R. L.), Walti (A.), Graber (R. P.), Flynd (E. H.), Hofihine (C. E.), Allfrey (V.) et Folkers (K.). - J. Am. Chem. Soc. 68, p. 772-776, 1946. Cité in Annual Review of Biochem. I949, 18, p. 559-594.

PECK (R. L.) et Lyons (J. E.). - Biochemistry of antibiotics. Annual Rev. of Biochemistry, 20, p. 367-4I4, I95I.

Plonsky (J. C.). - Bacitracin in poultry nutrition. Flour and feed, 52, 3, p. 34, I95I.

Powick (W. C.), Eiliss (N. B.), DALE (C. N.) et Zinober (M. R.). - Effect of nicotinic acid and vitamin $\mathrm{BI} 2$ and aureomycin on growth of pigs and 
on resistance to artificial infection with Salmonella Choleraesuis. $J$. of An. Sci., 10, 3, 617-23, I95I.

Reyniers (J. A.), Trexier (P. C.), Ervin (R. F.), Wagner (M.), Luckey (T. D.) et Gordon (H. A.). - A complete life-cycle in the germ free bantam chicken. Nature, 163, p. 67, I949 $a$.

REYNiERS (J. A.), TREXLER (P. C.), FRViN (R. F.), WAGNiR (M.), LUCKey (T. D.) et Gordon (H. A.). - Rearing germ free chickens. Lobund, Report, 2, p. 3, I949b.

RFyniers (J. A.), Trexler (P. C.), ERvin (R. F.), WAgner (M.), Luckey (T. D.) et Gordon (H. A.). - Some observations on germ-free bantam chickens. Lobund, Report, 2, p. II9, I949 c.

Reyniers (J. A.), Trexler (P. C.), ERvin (R. F.), Wagner (M.), Gordon (H. A.), Luckey (T. D.), Brown (R. A.), Mannering (G. J.) et CampBELI (C. J.). - Germ-free chicken nutrition I. Gross development and vitamin utilization studies employing White Leghorn chicks. $J$. of Nutr. 41, I, p. 3I-49, I95o.

REYNoldS (W. M.), LUTHER (H. G.) et WEBER (E. M.). - Br2 needs of chick ration by hog. Antibiotics and Chemoterapy, juillet I95I.

Richardion (L. R.), Blaycock (L. G.), Germann (L. H.) et Sherwood (R. M.). - Amino acids and vitamin BI2 as supplements to plant proteins for growing chicks. Feder. Proc., 8, p. 393, I949.

Richardson (D.), Catron (D. V.), Underkofler (L. A.), Maddock (H. M.) et Friediand (W. C.). - Vitamin BI2 requirement of male weanling pigs. J. of Nutr., 44, 3, p. 37I-38I, I950.

Rickes (E. L.), Brink (N. G.), KoniUszy (F. R.), Wood ('T. R.) et Folkkers (K.). - Crystaline Vitamin BI2. Science, 10\%, p. 396, I948 a.

Rickes (E. L.), Brink (N. G.), Koniuszy (F. R.), Wood (T. R.) et Folikers (K.). - Comparative data on vitamin $\mathrm{BI} 2$ from liver and from a new source, Streptomyces Griseus. Science, 108, p. 634-635, I948 b.

Robison (W. L.). - Présenté à la I2th annual. Ohio Animal Nutr. Conf. 8-9 nov., I95I.

Rosenberg (M. N.), Morikawo (W.) et Bushnei. (O. A.). - The effect of increasing concentrations of terramycin on the growth and intestinal microflora of chicks. Poul. Sci., 31, 4, p. 708-7I4, I952.

Rubin (M.), BIRD (H. R.) et RoThchiLd (J.). - A growth factor for chicks in the feces of hens. Poul. Sci., 25, p. 526-528, 1946.

Rusoff (L. L.). - A. P. F. supplements for calves. J. of $A n$. Sci., 9, 4, p. 666, I950.

RusofF (L. L.). - Antibiotic feed supplement (aureomycin) for dairy calves. J. Dairy Sci., 34, 7, p. 652-655, I95I.

Rusoff (L. L.) et Davis (A. V.). - Effect of aureomycin on growth of young calves weaned from milk at an early age. $J$. of Dairy Sci., 34, 6, p. 500, I950.

Rusoff (I. L.) et Davis (A. V.). - Présenté à 1'American Dairy Sci. Assoc. Knoxville, I95I.

Rusoff (L. L.), Davis (A. V.) et AlFord (J. A.). - Effect of aureomycin on growth of young calves weaned from milk at an early age. $J$. of Nutr., 45, 2, 289-299, I95I.

Sannié (C.). - Pigments et substances antibiotiques des champignons et des bactéries. Exposés annuels de Bioch. Med. 6e série, p. 225-280, r946.

SAUberlich (H. E.). - Effect of aureomycin and penicillin upon the vitamin requirement of the rat. $J$. of Nutr. 46, I, p. 99-I08, I952.

Savage (J. E.). - Antibiotics in poultry rations. Présenté à la second Ann. Miss. Formula Feed Conf. Univ. of Miss., 8-9 nov. I95o.

Schneider (B. H.), Goodwin (E. E.) et Ensminger (M. E.). - Antibiotic and methionine supplementation of three varieties of peas in ration for fattening growing pigs. $J$. of $A n$. Sci., 10, 4, p. I06I, I95I. 
Schweigert (B. S.), Shaw (J. H.), Philipps (R. H.) et Ellvehjem (C. A.). Dental caries in the cotton rat. III. Effect of different dietary carbohydrates on the incidence and extent of dental caries. $J$. of Nutr., 29, 6, p. 405, I945.

SCHWEIGERT (B. S.). - The animal protein factor. Nutr. Rev., \%, 8, p. 225-227, I949.

Scot' (M. L.). - The grass juice factor in turkey nutrition. Poul. Sci., 30, p. 293, I95I $a$.

Scotт (M. L.). -- Unidentified vitamins in turkeys nutrition. Proc. of the 1951 Cornell Nutr. Conf., p. 73-77, I95I $b$.

ScotT (M. L.), Heuser (G. F.) et NorRIs (L. C.). - Energy protein and unidentified ritamins in poult nutrition. Poul. Sci., 27, p. 773-780, I948.

ScotT (H. M.), Goffi (E. A.) et Glista (W. A.). - - The protein requirement of the chick as influenced by aureomycin. Poul. Sci., 31, 4, p. 751-752, I 952 .

Shapiro (S. K.), Sarles (W. B.). - Microorganisms in the intestinal tract of normal chickens. J. Bacteriology 58, p. 53I-544, I949.

SHEFFy (B. E.). - Recent advances in baby pig nutrition. Proceedings of the 1951 Cornell Nutrition Conf., p. 78-86, I95I.

Sheffy (B. E.), Phillips (P. H.), Grummer (R. H.) et Bohstedt (G.). - Comparison of growth responses of two day old pigs to streptomycin, aureomycin and crude A. P. F. alone or in combination with BI2. $J$. of $A n$. Sci., 11, I, p. 97-102, I952.

Shefnick (B. E.), Avecedo (C.), Grummer (R. H.), Philitips (P. H.) et BohsTEDT $(\mathrm{G}$.$) . - Comparison of growth responses to streptomycin, aureo-$ mycin and crude A. P. F. alone and in combination with BI2, on 2-day old pigs using a "synthetic " milk. $J$. of $A n, S c i ., 9,4$, p. 667, I950.

Singsen (E. P.), MatTerson (I. D.). - Effects of the animal protein factor on the growth of turkeys and chickens. Présenté au New England feedmens'meeting. Connecticut $\mathrm{Ag}$. Exp. Sta. août I 949 .

Skeggs (H. R.), HufF (J. W.), Wright (L. D.) et Bosshardt (D. M.). - The use of Lactobacillus leichmanii in the microbiological assay of the animal protein factor. $J$. Biol. Chem., 176, p. I459-I460, I948.

Slinger (S. J.), Gartley (K. M.), Peppere (W. F.) et Hili (D. C.). - The influence of A. P. F. supplements and antibiotics on the incidence and severity of white feather in turkeys. $J$. of Nutr., 43, 3, p. 345-355, I95I.

Smith (L. E.). - Purification of antipernicious anemia factors from liver. Nature, 161, p. 638-639, I948.

Speer (V. C.), Vohs (R. L.), Catron (D. V.), Maddock (H. M.) et Culbertson (C. C.). - Effect of aureomycin and animal protein factor on healthy pigs. Arch. Biochem. 29, 2, p. 452-453, r950.

Spies (T. D.), Lopez (G.), Milanes (F.), Stone (R. E.), Toca (R.), Aramburu (T.) et KARTUS (S.). - Observations on the effect of an animal protein factor concentrate on persons with the macrocytic anemia of pernicious anemia, of nutritional macrocytic anemia and of sprue, and on persons with nutritional glossitis. Blood, J. Hematol., 4, p. 8I9-826, I949.

STERn (J. R.), McGinnis (J.). - Présenté à 1'American Chemical Soc., II8th. National Meeting, 6 sept. I950.

Strokstan (E. L. R.), PAGe (A. C.), Pierce (J.), Frankin (A. L.), Jukes (T. H.), Henile (R. W.), EPstein (M.) et Welch (A. D.). - Activity of microbial animal protein factor concentrates in pernicious anemia. J. Lab. Clin. Med. 33, 7, p. 860-864, I948.

Stokstad (E. L. R.), Jukes (T. H.), Pierce (J.), Page (A. C.) et Franklin (A. L.) . - The multiple nature of the animal protein factor. J. of Biol. Chem., 180, 2, p. 647, I949. 
Stokstad (E. L. R.), Jornbusch (B. I.), Franklin (A. L.), Hoffman (K. F.), Hutchings (B. L.) et Jukes (T. H.). - Microbiological assay of vitamin BI2 by Lactobacillus leichmannii. Feder. Proc., 8, p. 257, I949 b.

Stokstad (E. I. R.). - Effect of aureomycin on animal nutrition. Présenté à la 3nd. Poul. and Feed Conf. Atlanta, I950.

Stokstad (E. L. R.) et Jukes ('T. H.). - Présenté à 1'American Chemical Soc. of Philacielphie, 9 avril. In Am. Chem. Soc. Abstr., avril I950, I2 aI950 $a$.

STokstad (E. L. R.) et Jukes (T. H.). - Further observations on the "A. P. F. ). Proc. Soc. Exp. Biol. Med., 73, p. 523, I950 b.

SrokstaD (E. L. R.) et JUkEs (T. H.). - Growth promoting effect of aureomycin on turkey poults. Poul. Sci., 29, 4, p. 6I I-6I2, I950 c.

S'rokstad (E. L. R.) et Jukes (T. H.). - Présenté à l'Informal Poult. Nutr. Conf. Atlantic City, I7-2 I avril, I950 $d$.

STOKSTAD (E. L. R.) et JukEs (T. H.). - Effects of various levels of vitamin BI2 upon growth response produced by aureomycin in chicks. Proc. Soc. Exp. Biol. Med. 76, I, p. 73-76, I95I.

Sunde (M. L.), Waibei, (P. E.), Cravens (W. W.) et Ellvehjem (G. A.). - A relationship between antibiotics, vitamin $\mathrm{BI} 2$ and choline and methionine in chick growth. Poul. Sci., 30, 5, p. 668-67 I, I95I.

TERRIL (S. W.) et KRIDER (J. L.). - A comparison of solvent soybean oil meals and the effect of adding aureomycin dried whey product with whey fermentation solubles and A. P. F. in drylot rations of weanling pigs. J. of An. Sci., 9, 4, p. 670, 1950.

Terril (S. W.), Wardein (W. K.), Becker (D. E.) et Meade (R. J.). - Antibiotics and unidentified growth factors for growing fattening pigs fed corn-soybean oil meal rationslin drylot. J. of An. Sci., 10, 4, p. I063, I95I.

Thayer (R. H.). - New factors for poultry feeding. Proc. of the Oklahoma Feed Cont., p. I8, I950.

THAYER (R. H.). - The effect of antibiotic feeding on the nutritive requirement of the chick. Présenté à la Convention of the Midwest Feed Manufacturers Assoc., I95I.

United States Department of A griculture. - Antibiotics prove powerful growth stimulant for unthrifty pigs. Communiqué, I95I.

Vestal (C. M.). - Minn. A. H. 5I. Depart. of An. Husb. Purdue Univ. West. Lafayette Indiana, sept. I950. In Proc. 1951, Cornell Nutr. Cont., p. I3.

VOELKER (H. H.) et CAsON (J. L.). - Antibiotics studies with dairy calves. J. An. Sci., 10, 4, p. 1065, I95I.

Wahlstrom (R. C.), Terrili (S. W.) et Johnson (B. C.). - Effect of antibacterial agents on growth of baby pigs fed a " synthetic " diet. Proceed. Soc. Exp. Biol. Med., 75, 3, p. 7IO-7 II, I950.

Waksmann (S. A.). - British Med. J. II, p. 595, I950. Cité in Annual Review of Bioch., I95I, 20, p. 367-4I4.

Wahlstrom (R. C.), Cohn (E. M.), Terrill (S. W.) et Johnson (B. C.). Growth effect of various antibiotics on baby pigs fed synthetic rations. J. An. Sci., 11, 3, p. 449-455, I952.

Waliace (H. D.), Ney (W. A.), AlberT (L. T.) et Cunha (T. J.). - Effect of reducing and discontinuing aureomycin supplementation during the growing fattening period of the pig., $J$. An. Sci., 10, 4, p. I066, I95I $a$.

WALIACE (H. D.), Ney (W. A.) et Cunha (T. J.). - Various antibiotics in cornpeanut meal rations for weanling pigs. $J$. of $A n$. Sci., 10, 4, p. Io66, I95I $b$.

Wasserman (R. H.), Cunningham (H. M.). - Unpublished data. Depart. An. Husb., Cornell Univ. Ithaca, New York. In Proc. 1951. Cornell Nutr. Cont., p. 37, I95I. 
Watrs (A. B.), Botkin (M. P.), Whatrey (J. A.) et Ross (O. B.) - - A. P. F. supplements for growing pigs. J. of $A n$. Sci., 9, 4, p. 67I, I950 a.

Watts (A. B.), Botkin (M. P.), Whatrey (J. A.) et Ross (O. B.). - A. P. F. supplements for growing fattening pigs. Oklahoma Agric. Exp. Sta. Misc. Publ., MP 22, p. 20-22, I950 b.

WERNER (G. M.). - Modern way of feeding the dairy calves. Feedstuffs, 23, 37, p. 60-64, I95I.

WhatLey (G. A.). - Cité in Feedstuffs, 22, 39, p. 52, I950.

Whitehili, (A.), Oleson (J. J.) et Hutchings (B. L.). - Sous presse, in Feedstuffs, I950, 22, 28, p. I7, I950 $a$.

Whitehil, (A. R.), Oleson (J. J.) et Hutchings (B. L.). - Stimulatory effects of aureomycin on growth of chicks. Proc. Soc. Exp. Biol. Med., \%, p. II-I3, I950 b.

Wintersteiner (O.) et Dutcher (J. D.). - Chemistry of antibiotics. Ann. rev. of Bioch., 18, p. 559-594, I 949 .

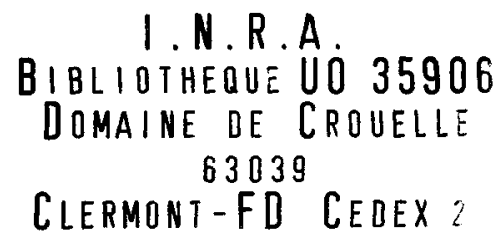

Le Directeur-Gérant : B. LACLAVIÈRE. 